\title{
Analysis and Optimization of Tooth Surface Contact Stress of Gears with Tooth Profile Deviations, Meshing Errors and Lead Crowning Modifications Based on Finite Element Method and Taguchi Method
}

\author{
Qiang $\mathrm{Li}^{1,2, *}$ and Liyang Xie ${ }^{1,2}$ \\ 1 School of Mechanical Engineering and Automation, Northeastern University, Shenyang 110819, China; \\ lyxieneu@163.com \\ 2 Key Laboratory of Vibration and Control of Aero-Propulsion System Ministry of Education, \\ Northeastern University, Shenyang 110819, China \\ * Correspondence: 1410093@stu.neu.edu.cn; Tel.: +86-138-981-35697
}

Received: 6 September 2020; Accepted: 12 October 2020; Published: 14 October 2020

\begin{abstract}
Based on the three-dimensional (3D) finite element method (FEM) and Taguchi method (TM), this paper analyzes the tooth surface contact stress (TSCS) of spur gears with three different influence factors: tooth profile deviations (TPD), meshing errors (ME) and lead crowning modifications (LCM), especially researching and analyzing the interactions between TPD, ME and LCM and their degree of influence on the TSCS. In this paper, firstly, a 3D FEM model of one pair of engaged teeth is modeled and the mesh of the contact area is refined by FEM software. In the model, the refined area mesh and the non-refined area mesh are connected by multi-point constraint (MPC); at the same time, in order to save the time of the FEM solution on the premise of ensuring the solution's accuracy, the reasonable size of the refined area is studied and confirmed. Secondly, the TSCS analyses of gears with one single influence factor (other factors are all ideal) are carried out. By inputting the values of different levels of one single factor into the FEM model, especially using the real measurement data of TPD, and conducting the TSCS analysis under different torques, the influence degree of one single factor on TSCS is discussed by comparing the ideal model, and it is found that when the influence factors exist alone, each factor has a great influence on the TSCS. Finally, through TM, an orthogonal test is designed for the three influence factors. According to the test results, the interactions between the influence factors and the influence degree of the factors on the TSCS are analyzed when the three factors exist on the gear at the same time, and it is found that the TPD has the greatest influence on the TSCS, followed by the lead crowning modified quantity. The ME is relatively much small, and there is obvious interaction between ME and LCM. In addition, the optimal combination of factor levels is determined, and compared with the original combination of a gear factory, we see that the contact fatigue performance of the gear with the optimal combination is much better. The research of this paper has a certain reference significance for the control of TPD, ME and LCM when machining and assembling the gears.
\end{abstract}

Keywords: finite element method; Taguchi method; tooth surface contact stress; tooth profile deviations; meshing errors; lead crowning modifications

\section{Introduction}

Gear transmission is the most important and widely used transmission in mechanical transmission. In particular, long-life precision gears are widely used in mechanical transmission systems with high reliability requirements, such as wind turbine gearboxes [1] and aero engines [2]. As the requirements 
for long-life precision gears are increasing, the requirements of machining accuracy, assembly accuracy and gear tooth modification are also growing, and these factors have a great influence on the tooth surface contact stress (TSCS) of gears.

At present, the main calculation methods of the TSCS include certain international standards such as ISO [3,4]. Most of these standard calculations are based on experience and some experimental results. However, when there are different tooth profile deviations (TPD), meshing errors (ME) and lead crowning modifications (LCM) on the tooth surface, since the influence coefficient in the calculation formula is derived from research results and field experience, and the determination of some coefficients is affected by many factors, it is difficult to determine the value of the influence coefficients. In addition, the interaction between each influence coefficient is not reflected in the formula. Therefore, the above methods cannot perform accurate calculations [5]. Therefore, it is very important to accurately analyze and calculate the TSCS of gears with the above influence factors, especially when the three factors exist at the same time.

At present, there are a lot of studies on the influence of TPD, ME and LCM on gear performance. Sennba [6] studied the influence of LCM gears and gear shaft misalignment on TSCS and tooth root bending stress through a large number of tests as early as 1974. Ottewill et al. [7] derived an equation of motion incorporating an error function and losses at the mesh interface to study the effect of TPD on the rattling of idling gears. They compared the theoretical and experimental trajectories by way of time domain plots as well as via contour plots, and for most profile error functions, good agreement was achieved between the model and experimental data. The results showed that the TPD weakened the contact strength and bending strength of gears, and intensified the vibration and noise of gears [7]. Ma et al. [8] introduced a method to analyze the dynamic load of the planetary gears in the gearbox of a PT6 turboprop engine, and a rigorous dynamic analysis, which included the effects of nonlinear tooth stiffnesses, ring gear flexibility, gear errors and misalignments, was necessary to determine dynamic tooth loads and the load sharing among the planets. The results were presented from sample calculations for a typical gear stage [8]. Bodas et al. [9] used an advanced contact mechanics model of a planetary gear set to study the effects of a series of manufacturing and assembly errors on the load distribution between planetary gears. Three different groups of errors were considered: (i) time-invariant, assembly-independent errors, (ii) time-invariant, assembly-dependent errors, and (iii) time-varying, assembly-dependent errors. With such errors present, the planet load sharing characteristics of an $n$-planet system ( $n=3$ to 6$)$ were investigated for different piloting configurations under both static and dynamic conditions [9]. In view of the shortcomings of traditional analysis methods (the complicated integral equations make it difficult to instantly obtain proper results for some tooth flanks distorted by heat treatment, and the repetition calculation may not converge, especially in light load conditions), Miyosh et al. [10] proposed a new composite analysis method which can quickly calculate the contact load distribution on the tooth surface of helical gears under any load condition. Although a large number of scholars have carried out experimental research and theoretical research, these studies have not put forward a method or model that can efficiently and accurately calculate the tooth stress when the above three factors exist at the same time, especially for the influence of these factors on the TSCS when there are different levels of these factors.

In recent years, more and more scholars have used the finite element method (FEM) to model gears, and then conduct the simulation and analysis of the gear performance, and confirm that the FEM is a very effective method for the simulation analysis of gears. Li [5] has used the FEM to calculate the TSCS and the tooth root stress with manufacturing errors, tooth profile modifications and assembly errors. By comparing the test results of other scholars and their own test results, it was found that the calculation results of the FEM including ME and LCM are relatively consistent with the test results, which indicates the accuracy of the FEM. It also was found that TPD, ME and LCM exert great effects on the TSCS of the gears. The TSCS and the tooth root stress of the same pair of gears were also calculated by ISO (International Organization for Standardization) and JGMA (Japan Gear Manufacture Association) standards for comparing with the FEM results, and the accuracy and efficiency of the 
finite element model have been verified [5]. However, the scholar only studied the influence of a single influence factor on TSCS under a single torque load through the finite element method, and did not study the influence of different levels of influence factors on the TSCS under different torques. In addition, although the scholar conducted a simple finite element analysis when all factors existed at the same time, the influence degree of each factor on the TSCS and the interaction between the factors have not been studied and analyzed. Wang et al. [11] used the FEM to analyze the TSCS and transmission error of the gears with tooth profile errors, and the results showed that mesh stiffness decreases and loaded transmission error and the maximum tooth contact stress grow when increasing the tooth lead crown relief. Lin et al. [12] used the FEM to model the machining errors, assembly errors and tooth modifications of the gear transmission system to obtain the static transmission error, so as to analyze the coupled transmission error of a helical gear system. Although there are a lot of FEM studies on the performance of gears with different influencing factors, the main highlight is the influence of one single factor on TSCS, and this does not consider the interaction between various factors, especially the influence of these factors on the gear performance when they exist at the same time.

In addition, most studies often only study the influence of one single precision grade of TPD on gear performance, or assume that the distribution form of TPD on the tooth surface is a sine function, which does not represent the influence of the actual TPD of different precision grades on the gear performance.

When researching the interaction of various factors and the influence degree of various factors on TSCS when they exist at the same time, this paper uses the Taguchi method (TM). The TM has been widely used for the design and analysis of various engineering fields, such as gear manufacturing processes [13], chemical industry [14], soil [15] and energy [16], and it has been demonstrated to be a powerful tool due to its simplicity and robustness [17]. Through the TM, within the specified level range, the optimal level combination of influence factors can also be obtained to determine the optimal TPD grade, ME and LCM quantity in order to obtain a relatively minimum TSCS.

In summary, compared with the experimental method and theoretical method, the FEM can obtain the TSCS more effectively, accurately and intuitively, such that a 3D FEM model of one pair of engaged teeth is modeled and the mesh of the contact area is refined by FEM software in this paper. Then, by inputting the values of different levels of one single factor into the FEM model, especially using the real measurement data of TPD, and conducting the TSCS analysis under different torques, the influence degree of one single factor on TSCS is discussed by comparing the ideal model. In view of the fact that other scholars rarely study the degree of influence of each factor on TSCS and the interaction between them when all factors exist at the same time, in this paper, through the TM, the interactions between the influence factors and the influence degree of the factors on the TSCS are studied when the three factors exist on the gear at the same time, and the optimal combination of factor levels can also be obtained.

The general analysis steps of this paper are shown in Figure 1. 


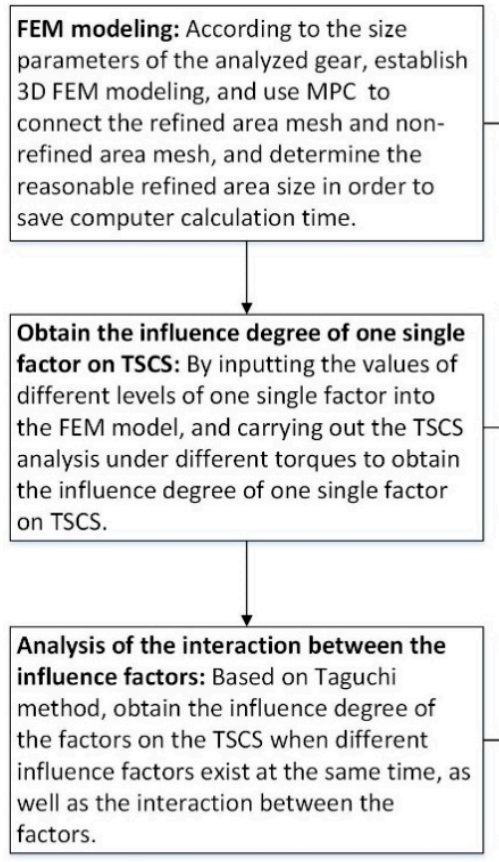

\begin{tabular}{|c|}
\hline Mesh refinement for tooth surface contact area. \\
\hline $\begin{array}{c}\text { Use MPC to connect the refined area mesh and non-refined } \\
\text { area mesh. }\end{array}$ \\
\hline Determine the reasonable refined area size. \\
\hline
\end{tabular}

Input the real measurement of TPD in the refined area of tooth surface, and analyze the influence of TPD of different precision grades on the TSCS under different torques.

\begin{tabular}{|l} 
grades on the TSCS under different torques. \\
$\begin{array}{c}\text { Input the Me in the FEM modeling, and analyze the influence of } \\
\text { different ME on the TSCS under different torques. }\end{array}$ \\
$\begin{array}{c}\text { Input the LCM in the refined area of tooth surface, and analyze } \\
\text { the influence of different LCM quantities on the TSCS under } \\
\text { different torques. }\end{array}$
\end{tabular}

\begin{tabular}{|} 
Problem description, determinations of quality characteristic, \\
ideal function and the control factors.
\end{tabular}

Figure 1. The general analysis steps.

\section{FEM Modeling}

\subsection{Determination of Gear Engagement Position}

In this paper, a pair of gears with the same parameters are selected for engagement. The basic size parameters of the gears are shown in Table 1. Through calculation, the coincidence degree of the engaged gear is 1.56 so there are engagement positions of a single pair of teeth in the entire engagement circle.

Table 1. The basic size parameters of the gears.

\begin{tabular}{cccccccccc}
\hline $\begin{array}{c}\text { Normal } \\
\text { Modulus }\end{array}$ & $\begin{array}{c}\text { Tooth } \\
\text { Number }\end{array}$ & $\begin{array}{c}\text { Pressure } \\
\text { Angle }\end{array}$ & $\begin{array}{c}\text { Addendum } \\
\text { Coefficient }\end{array}$ & $\begin{array}{c}\text { Clearance } \\
\text { Coefficient }\end{array}$ & $\begin{array}{c}\text { Helix } \\
\text { Angle }\end{array}$ & $\begin{array}{c}\text { Tooth } \\
\text { Width }\end{array}$ & $\begin{array}{c}\text { Modification } \\
\text { Coefficient }\end{array}$ & $\begin{array}{c}\text { Poisson } \\
\text { Ratio }\end{array}$ & $\begin{array}{c}\text { Elastic } \\
\text { Modulus }\end{array}$ \\
\hline $2 \mathrm{~mm}$ & 20 & $20^{\circ}$ & 1 & 0.25 & $0^{\circ}$ & $5 \mathrm{~mm}$ & 0 & 0.25 & $2.07 \times 10^{5} \mathrm{MPa}$ \\
\hline
\end{tabular}

As it can be seen from the literature [18] and Figure 2, for ideal gears, when the engagement positions are single-pair tooth contact positions (positions 16-27), the single pair of teeth bears all the applied load, that is to say, for one period of tooth engagement, the maximum TSCS occurs in the positions 16-27. As such, this paper defines the engagement position of the TSCS analysis at the position of the gear pitch circle, and the TPD, ME and LCM of the tooth surface are input and adjusted based on this engagement position, so as to research and analyze the influence of different factors on the TSCS. 


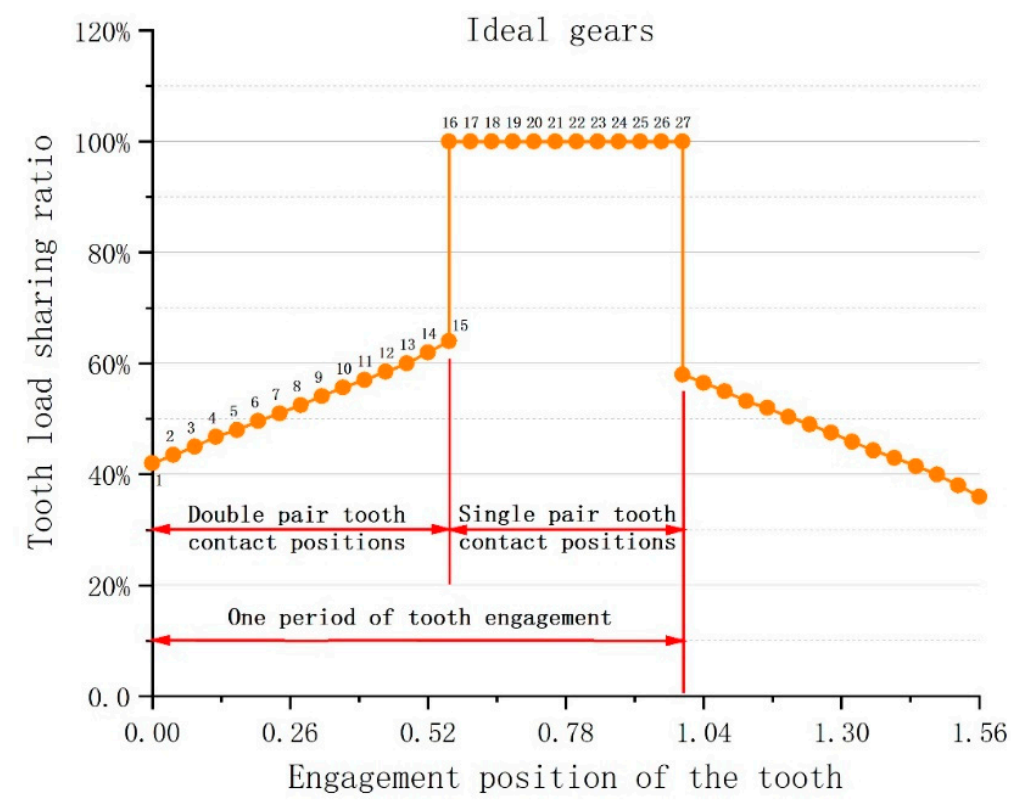

Figure 2. The load-sharing ratios of the ideal gears.

\subsection{Multi-Point Constraint (MPC)}

When the gears are engaged, the stress field gradient near the contact line is very large. The contact area needs high-density mesh to capture the contact state. The smaller the element size of the FEM model is, the smaller the stress difference between the elements is, and the higher the solution accuracy of the model is, but the longer the solution time of the model is. In order to balance the contradiction between solution accuracy and solution time, it is necessary to determine a reasonable mesh density transition boundary.

In order to ensure the solution accuracy of the FEM, it is necessary to refine the mesh of the contact area. In this paper, MPC is used to connect the refined mesh with the non-refined mesh. As shown in Figure 3, the orange part is the refined area of the tooth mesh. Partial FEM parameters are shown in Table 2.

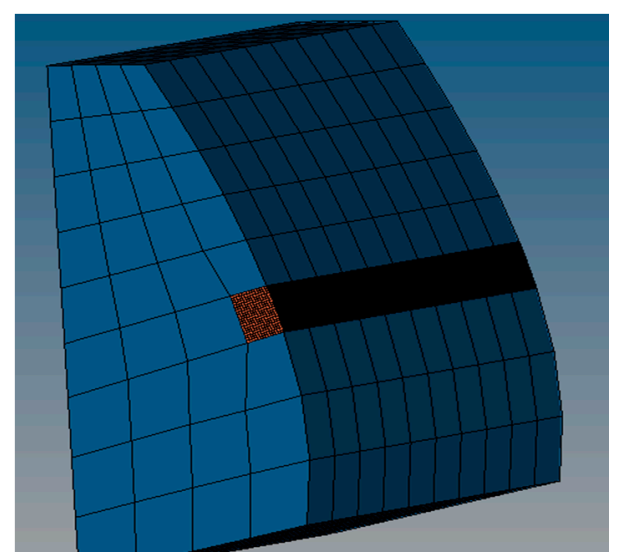

Figure 3. The refined area of the tooth mesh.

Table 2. The finite element method (FEM) parameters.

\begin{tabular}{ccccc}
\hline Type of Main Elements & Contact Surface Element & Target Surface Element & Friction Coefficient & Material Density \\
\hline Solid185 & Conta173 & Targe170 & 0.1 & $7.8 \times 10^{-9} \mathrm{t} / \mathrm{mm}^{3}$ \\
\hline
\end{tabular}


MPC, that is, multi-point constraint, establishes a multi-point constraint relationship. Through MPC, different meshes can be connected. If the geometry is not connected in the topology, different geometric parts can be meshed respectively, and then the FEM models can be connected with the MPC. A simple example is shown in Figure 4; Figure 4a shows the MPC connection of refined mesh and non-refined mesh, while Figure $4 \mathrm{~b}$ shows no MPC connection and the entire mesh has been refined. Both models are solved using SHELL181 element, in which the shell element thickness is $0.01 \mathrm{~m}$, the elastic modulus $\mathrm{E}=2.1 \times 10^{5} \mathrm{MPa}$, and the Poisson's ratio $\mu=0.3$. Figure $4 \mathrm{c}$ shows the loading type and boundary conditions, and the two models have the same type of boundary conditions and linear pressure loads, in which the linear pressure is $10 \mathrm{~N} / \mathrm{m}$. Figure 4d,e show the analysis results of FEM, and the maximum stress on both models is $6.63 \mathrm{MPa}$. According to the stress nephogram and solution results, for the FEM model of MPC connection, when the size of the refined area is large enough, that is to say, when the distance between the MPC connection position and the stress analysis position is far enough, the solution results are basically consistent with the results of the entire refined mesh model. Therefore, in this paper, the mesh of the refined area and non-refined area is connected by the MPC, and in order to save the time of FEM analysis, and at the same time ensure the accuracy of the solution, the optimal size of the refined area will be studied and analyzed to determine the mesh transition boundary position.

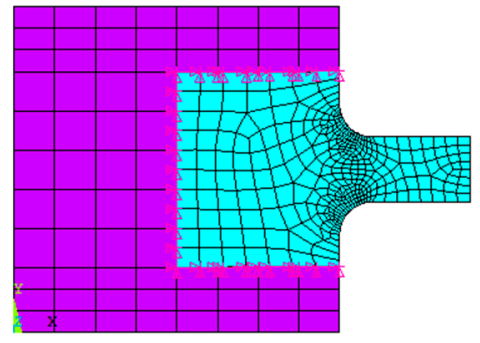

(a) MPC connection

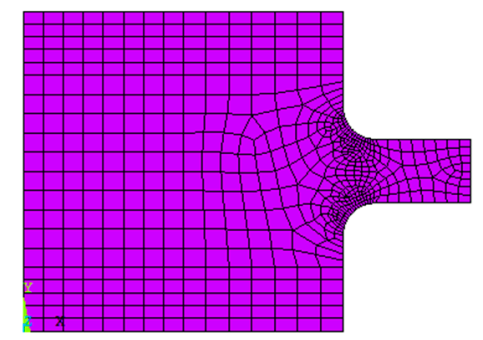

(b) Consistent mesh

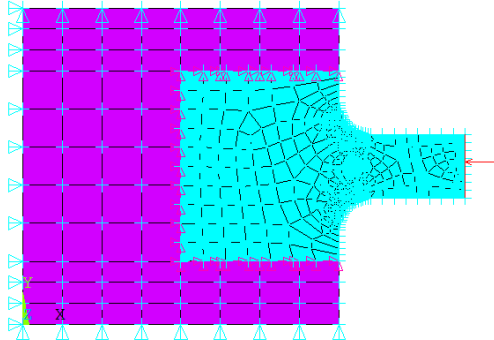

(c) Loading type, boundary conditions

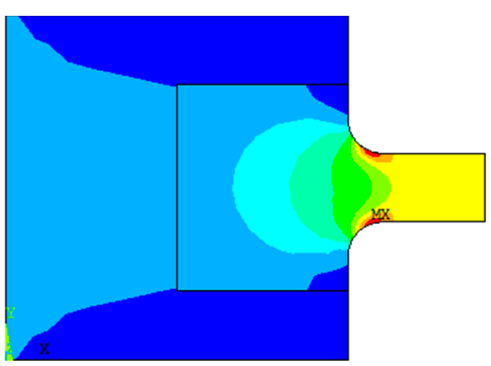

(d) MPC connection: $\mathrm{SMAX}=6.63 \mathrm{MPa}$

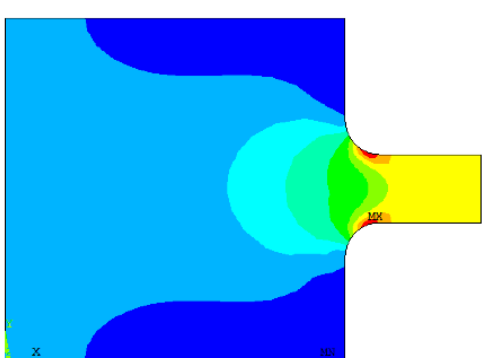

(e) Consistent mesh: $\mathrm{SMAX}=6.63 \mathrm{MPa}$

Figure 4. Multi-point constraint (MPC) connection.

\subsection{Determination of Mesh Transition Boundary Position}

\subsubsection{Hertz Contact Theory}

In order to determine the optimal position of the mesh transition boundary, it is necessary to establish different-sized refined areas to verify the accuracy of the model. The engagement of involute cylindrical gears is similar to the contact between two cylinders, so the accuracy of the FEM solution can be verified by Hertz contact theory [19]. Figure 5 is a Hertz contact model, where $F$ is the normal force applied, $\sigma_{H \max }$ is the maximum contact stress on the contact surface, $b$ is the half width of the 
contact zone, $a$ is the contact length, and $\rho_{1}$ and $\rho_{2}$ are the curvature radius of the two cylinders. $\sigma_{H \max }$ and $b$ can be calculated by Equations (1) and (2).

$$
\begin{gathered}
\sigma_{\text {Hmax }}=\sqrt{\frac{F}{\pi \times a} \times \frac{\left(\frac{1}{\rho_{1}}+\frac{1}{\rho_{2}}\right)}{\left(\frac{1-\mu_{1}^{2}}{E_{1}}+\frac{1-\mu_{2}^{2}}{E_{2}}\right)}} \\
b=\sqrt{\frac{4 \times F}{\pi \times a} \times \frac{\left(\frac{1-\mu_{1}^{2}}{E_{1}}+\frac{1-\mu_{2}^{2}}{E_{2}}\right)}{\left(\frac{1}{\rho_{1}}+\frac{1}{\rho_{2}}\right)}}
\end{gathered}
$$

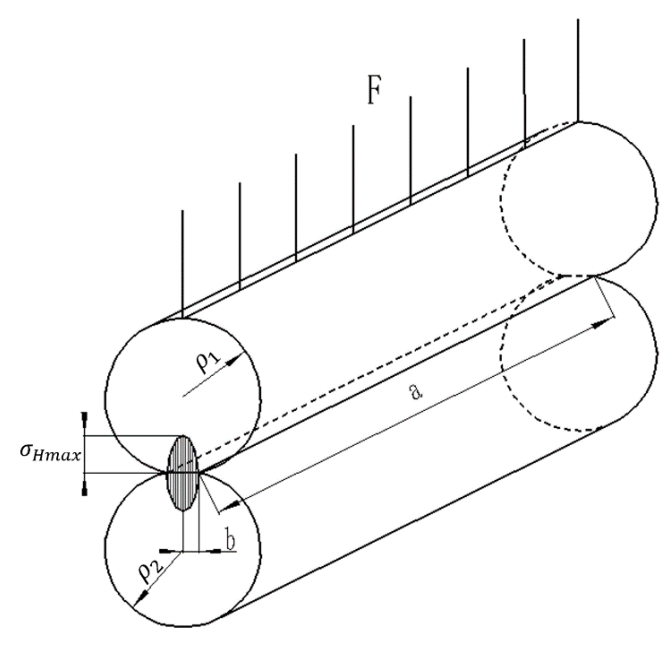

Figure 5. Hertz contact model.

In Equations (1) and (2), $\mu_{1}$ and $\mu_{2}$ are the Poisson's ratio of the materials of cylinder 1 and cylinder 2, and $E_{1}$ and $E_{2}$ are the elastic modulus of the materials of cylinder 1 and cylinder 2. Treat the cylindrical contact as the engaged contact of two gear teeth; $a$ is equivalent to the tooth width, and $F$ is equivalent to the normal force of the tooth surface contact. In Equations (3)-(5), $F_{t}$ is the circumferential force produced by torque, $\alpha$ is the pressure angle, and $d_{1}$ and $d_{2}$ are the diameters of the pitch circles.

$$
\begin{gathered}
F=\frac{F_{t}}{\cos \alpha}=\frac{2 \times T}{d_{1} \times \cos \alpha} \\
\rho_{1}=\frac{d_{1} \times \sin \alpha}{2} \\
\rho_{2}=\frac{d_{2} \times \sin \alpha}{2}
\end{gathered}
$$

The maximum torque $T$ applied to the engaged gear is defined as $25 \mathrm{~N} \cdot \mathrm{m}$. Combining Equations (1)-(5), the TSCS of the engaged gear is calculated to be $1653.75 \mathrm{MPa}$, and the half width of the contact zone is $0.10 \mathrm{~mm}$. The TSCS has basically reached the contact fatigue limit of carburized alloy steel gears with high material quality and heat treatment quality. Therefore, in this paper, the maximum torque applied to the gears will not exceed $25 \mathrm{~N} \cdot \mathrm{m}$. If the size of the refined area determined under this torque can meet the solution accuracy, the solution accuracy can also be guaranteed when the torque is less than $25 \mathrm{~N} \cdot \mathrm{m}$. 


\subsubsection{Determination of Mesh Transition Boundary Position}

As shown in Figure 6, take the length of $b$ as the basic unit of the refined area size, and set the MPC boundary of the contact area as $w \times h$. Firstly, set $w \times h$ as $8 b \times 8 b$ to refine the mesh, and the FEM model of a pair of ideal teeth is shown in Figure 7.

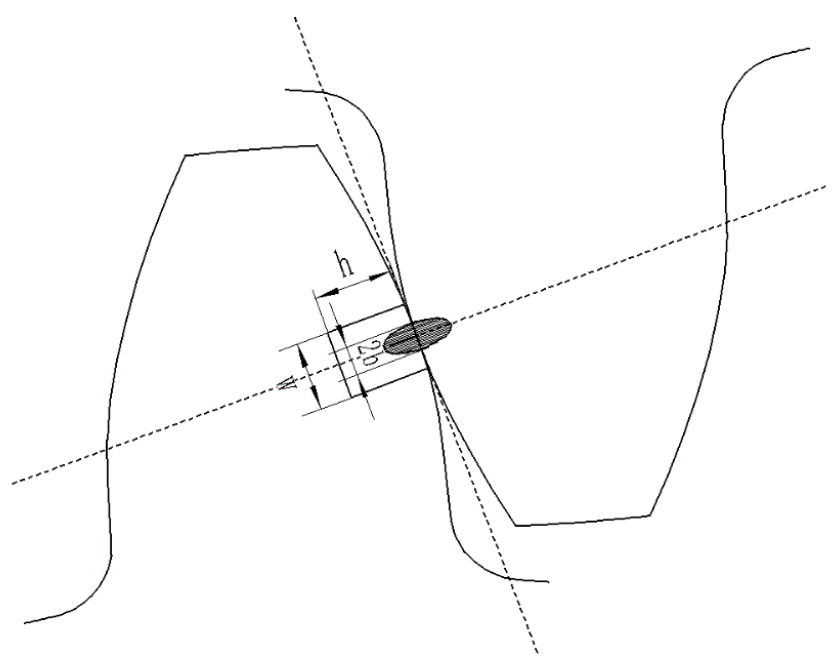

Figure 6. MPC boundary.

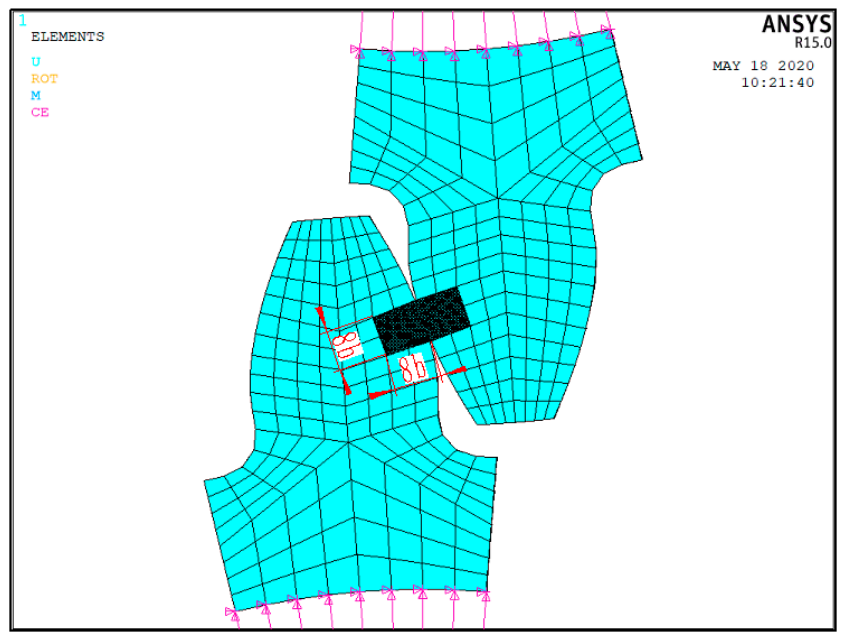

Figure 7. Finite element method (FEM) model.

Apply a torque of $25 \mathrm{Nm}$ to the FEM model and conduct FEM solution. The Von Mises stress nephogram is shown in Figure 8. It can be seen from Figure 8 that the stress gradient of the gear at the engagement position is very large, but the stress decreases sharply at a certain distance from the maximum stress position, and at a position less than $4 b$ below the tooth surface, the stress gradient is very gentle. Therefore, when the size of the refined area is $w \times h=8 b \times 8 b$, the influence of the MPC on the solution accuracy of the model can be ignored. It can be seen from Figure 9 that the maximum TSCS solved by the FEM model is $1676.23 \mathrm{MPa}$, and the relative error is only $1.36 \%$ when compared with the $1653.75 \mathrm{MPa}$ calculated by the Hertz contact theory. 


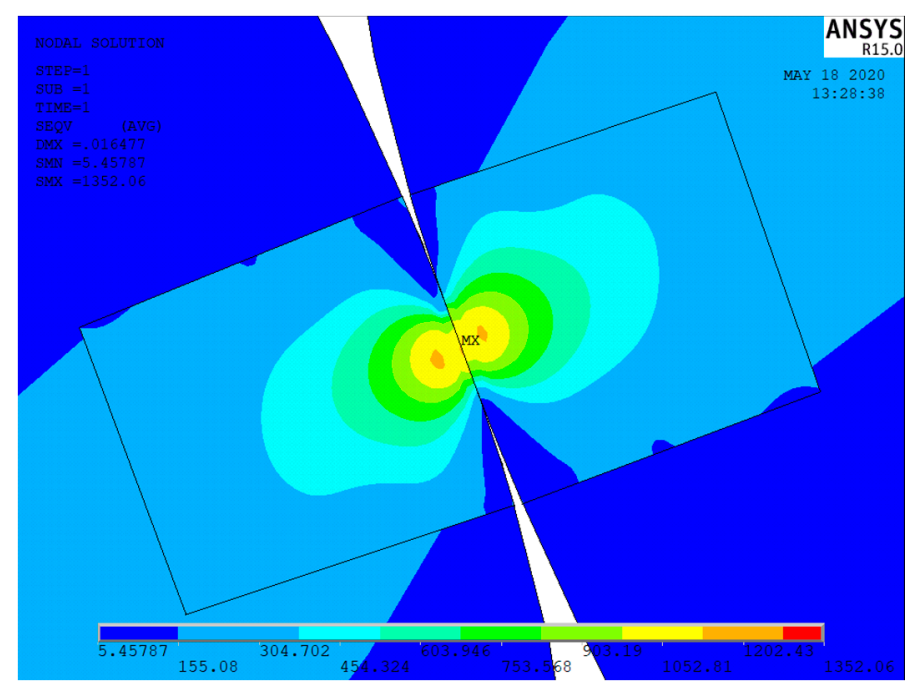

Figure 8. The Von Mises stress nephogram of solution result.

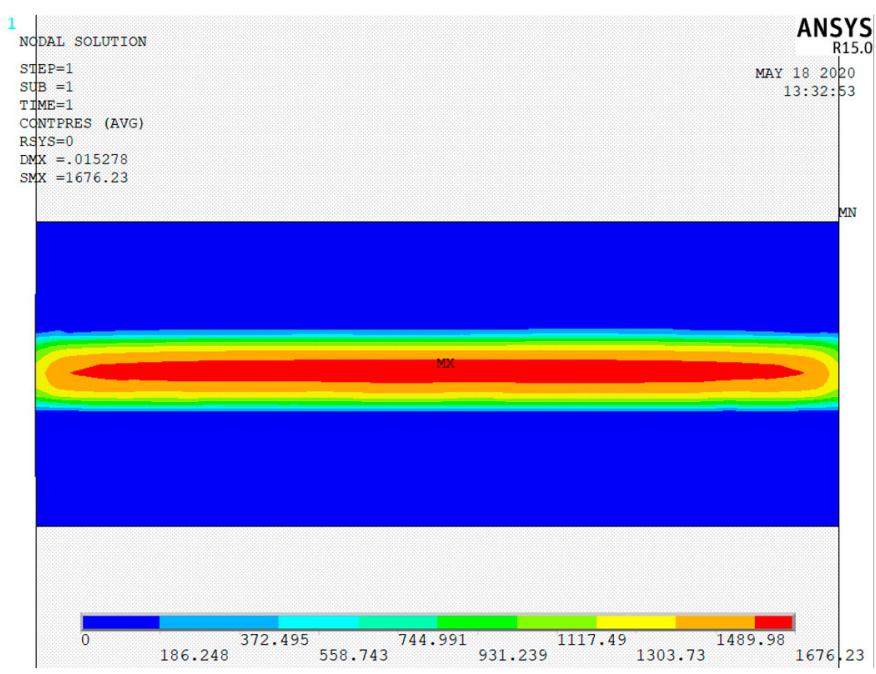

Figure 9. The maximum tooth surface contact stress (TSCS) solved by the FEM model.

When the size of the refined area is $w \times h=8 b \times 8 b$, the solution accuracy meets the requirements, so the size of the refined area is further reduced. Figure 10 shows the Von Mises stress nephograms corresponding to the refined areas of different sizes, and Table 3 is the corresponding maximum TSCS. It can be seen from Figure 10 and Table 3 that when $w \times h=4 b \times 4 b$ and $w \times h=4 b \times 3 b$, the stress gradients at the MPC connection position are relatively gentle, and the errors between the maximum TSCS and that calculated by the Hertz contact theory are within $2.5 \%$, the solution accuracy of the model still meets the requirements. With a further reduction in the size of the refined area, when $w \times h=4 b \times 2 b$ and $w \times h=3 b \times 4 b$, the stress gradients at the MPC connection position are relatively large, and the errors between the maximum TSCS and that calculated by the Hertz contact theory are also relatively large. 


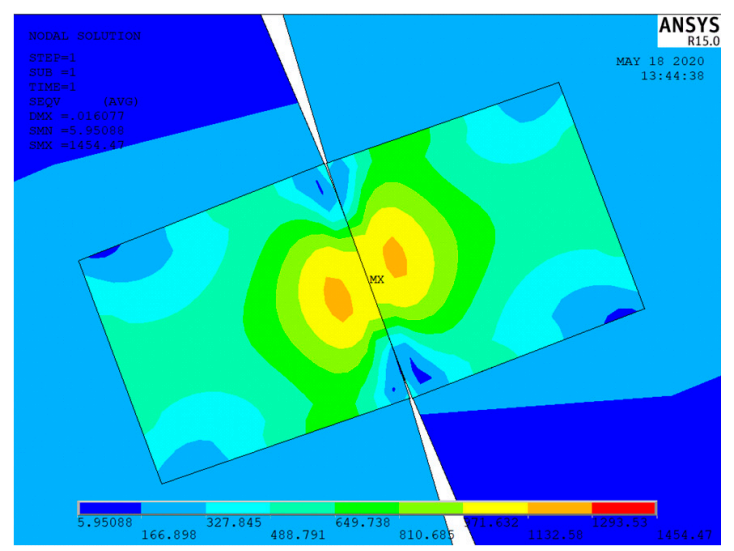

(a) $w \times h=4 b \times 4 b$

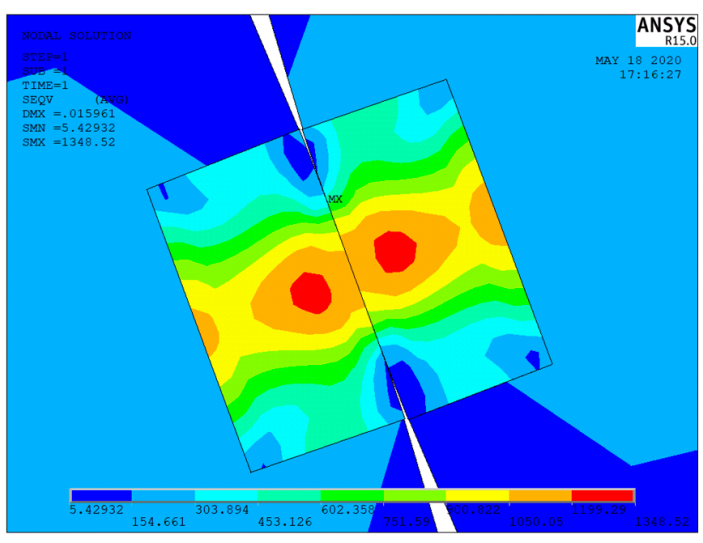

(c) $w \times h=4 b \times 2 b$

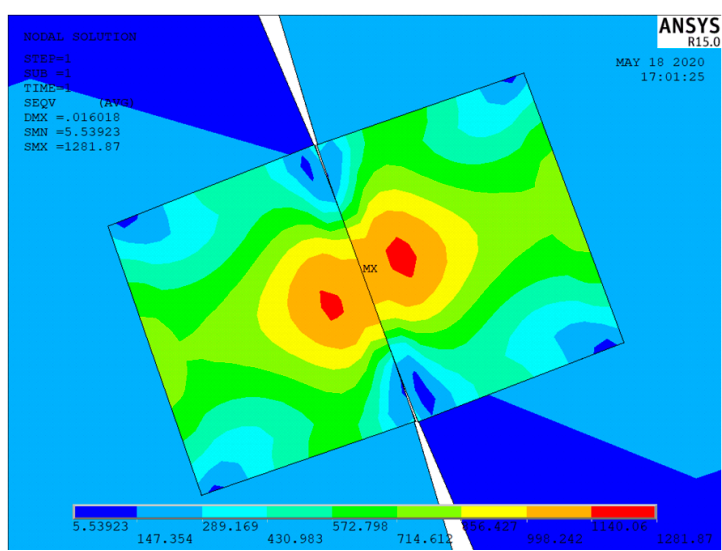

(b) $w \times h=4 b \times 3 b$

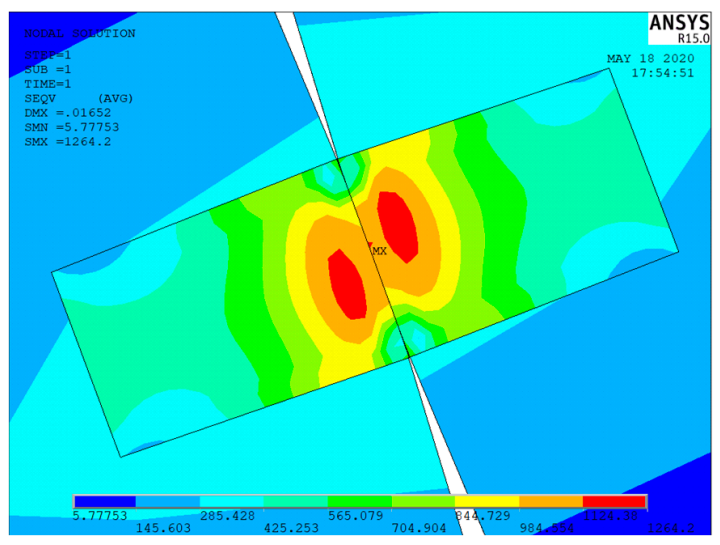

(d) $w \times h=3 b \times 4 b$

Figure 10. The Von Mises stress nephogram of solution result.

Table 3. The maximum tooth surface contact stress (TSCS) in refined areas of different sizes.

\begin{tabular}{cccc}
\hline $\boldsymbol{w} \times \boldsymbol{h}$ & The Maximum TSCS (MPa) & The Errors of TSCS & Time (min) \\
\hline Hertz contact theory & 1653.75 & & \\
$8 b \times 8 b$ & 1676.23 & $1.36 \%$ & 75 \\
$4 b \times 4 b$ & 1682.93 & $1.76 \%$ & 9 \\
$4 b \times 3 b$ & 1693.59 & $2.41 \%$ & 6 \\
$4 b \times 2 b$ & 1754.98 & $6.12 \%$ & 4 \\
$3 b \times 4 b$ & 1712.73 & $3.57 \%$ & 6 \\
\hline
\end{tabular}

In addition, the solution time shows that the larger the size of the refined area, the longer the solution time, especially when the solution time of $w \times h=8 b \times 8 b$ is more than 10 times that of $w \times h=4 b \times 3 b$, so if the full tooth mesh is refined, the calculation time will be much longer.

In conclusion, for the TSCS analysis of the ideal gear researched in this paper, the reasonable size of the refined area should be at least $w \times h=4 b \times 3 b$, but the TSCS values of the gears with TPD, ME or LCM are much larger than that of the ideal gear. Therefore, according to the Hertz contact theory, assuming that the maximum TSCS of the gear with influence factors is 1.5 times that of the ideal gear, the contact half-width should also be increased by 1.5 times, as should the half-width of the contact zone $b$. Therefore, when analyzing the TSCS of the gears with influence factors, the reasonable size of the refined area should be at least $w \times h=6 b \times 4.5 b=0.60 \mathrm{~mm} \times 0.45 \mathrm{~mm}$. 
In addition, referring to the calculation method of TSCS in ISO6336 [3,4], the accuracy of FEM can be further verified. According to Equation (6) and Table 4, the TSCS of the gear is 1657.28 MPa, and the TSCS error between the $w \times h=4 b \times 3 b$ and Equation (6) is only $2.19 \%$.

$$
\sigma_{H}=Z_{D} Z_{H} Z_{E} Z_{\varepsilon} Z_{\beta} \sqrt{\frac{F_{t}}{d_{1} b} \frac{u+1}{u}} \sqrt{K_{A} K_{\gamma} K_{V} K_{H \beta} K_{H \alpha}}
$$

Table 4. Meanings of the symbols used in Equation (6).

\begin{tabular}{ccc}
\hline Symbol & Description & Value \\
\hline$\sigma_{H}$ & Contact stress (MPa) & 1657.28 \\
$Z_{D}$ & Single pair tooth contact factors for the wheel & 1.0 \\
$Z_{H}$ & Zone factor & 2.5 \\
$Z_{E}$ & Elasticity factor & 187.5 \\
$Z_{\varepsilon}$ & Contact ratio factor & 1.0 \\
$Z_{\beta}$ & Helix angle factor & 1.0 \\
$F_{t}$ & Tangential force at the working pitch circle $(\mathrm{N})$ & 1250 \\
$d_{1}$ & Diameter (mm) & 40 \\
$b$ & Face width (mm) & 5 \\
$u$ & Gear ratio & 1.0 \\
$K_{A}$ & Application factor & 1.0 \\
$K_{\gamma}$ & Mesh load factor & 1.0 \\
$K_{V}$ & Dynamic factor & 1.0 \\
$K_{H \beta}$ & Face load factor & 1.0 \\
$K_{H \alpha}$ & Transverse load factor & 1.0 \\
\hline
\end{tabular}

\section{TSCS Analysis of Gear with TPD, ME or LCM}

\subsection{TSCS Analysis of Gear with TPD}

All actual manufactured gears have TPD. According to the definition of TPD in the ISO 1328-1:2013 standard [20], TPD refers to the amount of actual tooth profile deviating from the designed tooth profile, which is calculated in the end plane and perpendicular to the involute tooth profile. According to the gear precision grade, gear module and pitch circle diameter, the range of the total TPD value under the precision grade is specified in the ISO standard [20].

Figure 11 shows the node distribution form of the tooth surface refined area. Each node on the tooth surface of the area is numbered, then the corresponding TPD is input to each node, and these TPD values come from the measured data of the gear factory. Figure 12 shows the tooth surface state after inputting the measured TPD of a grade 4 precision gear, and the unevenness of the tooth surface can be vaguely seen from the figure. We enlarged the tooth surface (shadow part) of the refined area in Figure 12, and show the enlarged effect in Figure 13. In Figure 13, the $X$ axis direction is the direction from tooth root to tooth top, the $\mathrm{Y}$ axis direction is the direction of the tooth width, and the $\mathrm{Z}$ axis represents the TPD value. After enlarging the refined area, it can be clearly seen that the tooth surface is uneven.

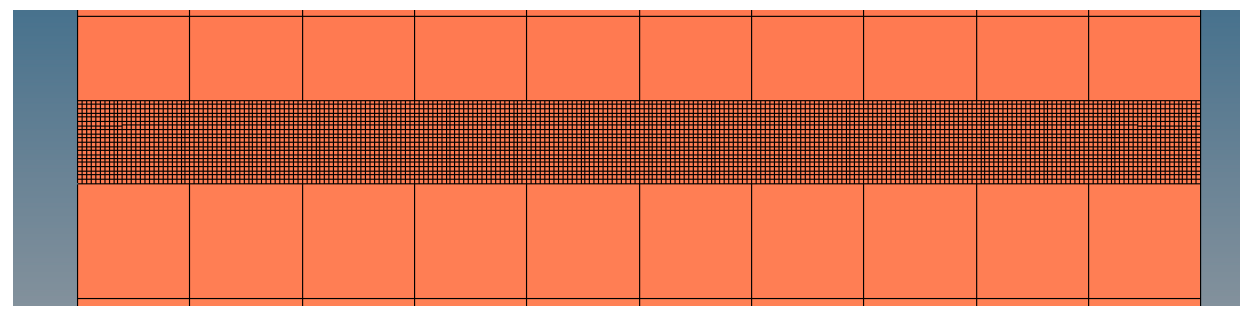

Figure 11. The node distribution form of the tooth surface's refined area. 


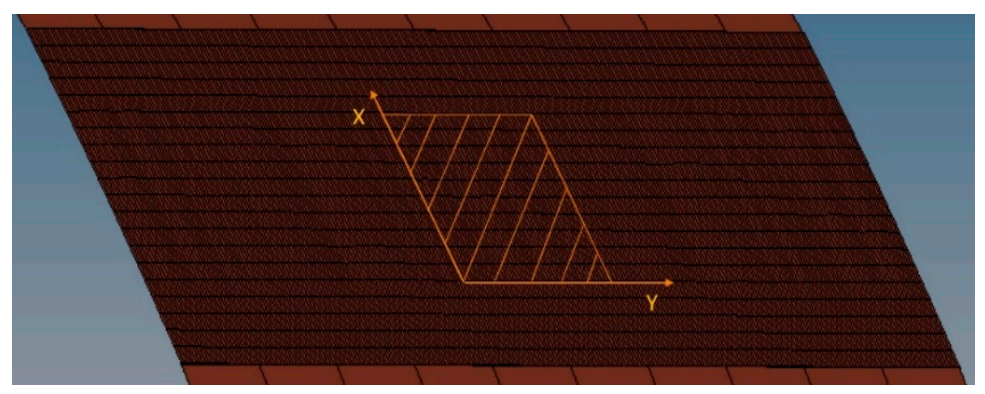

Figure 12. The tooth surface state after inputting the measured tooth profile deviations (TPD).

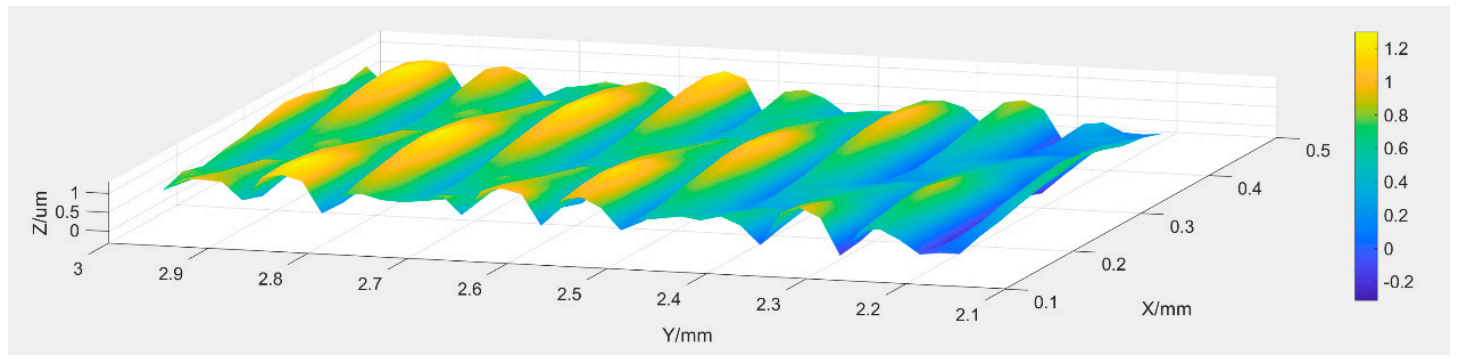

Figure 13. The enlarged effect of the tooth surface refined area with TPD.

This paper also proposes a method to obtain the TPD of other precision grade gears when the TPD value of the grade 4 precision gear is known. As shown in Table 5, according to the range of the total TPD value of each precision grade gear, it is considered that:

$$
f_{n i}: f_{4 i}=F_{n}: F_{4}
$$

where $F_{\mathrm{n}}$ is the upper limit value of the total TPD value of the grade $n$ precision gear, and $f_{n i}$ is the actual TPD value of each node of the grade $n$ precision gear ( $i$ is the node number), so the TPDs of the refined areas of other precision grade gears can be obtained by Equation (7).

Table 5. The total tooth profile deviations (TPD) value of each grade precision gear.

\begin{tabular}{ccccccccccc}
\hline \multirow{2}{*}{$\begin{array}{c}\text { Pitch Circle } \\
\text { Diameter }(\mathbf{m m})\end{array}$} & $\begin{array}{c}\text { Module } \\
(\mathbf{m m})\end{array}$ & $\mathbf{0}$ & $\mathbf{1}$ & $\mathbf{2}$ & $\mathbf{3}$ & $\mathbf{4}$ & $\mathbf{5}$ & $\mathbf{6}$ & $\mathbf{7}$ \\
\cline { 3 - 11 } & \multirow{2}{*}{$20<\mathrm{d} \leq 50$} & $0.5 \leq \mathrm{m} \leq 2$ & 0.9 & 1.2 & 1.8 & 2.5 & 3.5 & 5.0 & 7.0 & 10.0 \\
& & $\mu \mathrm{m}$ & $\mu \mathrm{m}$ & $\mu \mathrm{m}$ & $\mu \mathrm{m}$ & $\mu \mathrm{m}$ & $\mu \mathrm{m}$ & $\mu \mathrm{m}$ & $\mu \mathrm{m}$ \\
\hline
\end{tabular}

In this paper, the FEM contact analyses for grade 2, 4 and 6 precision gears with only TPD are carried out, respectively. Figure 14 is the result of the FEM solution when the torque is $10 \mathrm{Nm}$, and, from Figure 14a to Figure 14d, shows the TSCS nephograms of ideal gear, grade 2 precision gear, grade 4 precision gear and grade 6 precision gear. It can be seen that the TSCS with TPD presents irregular distribution on the tooth surface, and with the reduction of gear precision, the gradient of the local TSCS increases gradually, and the maximum TSCS also increases accordingly. 


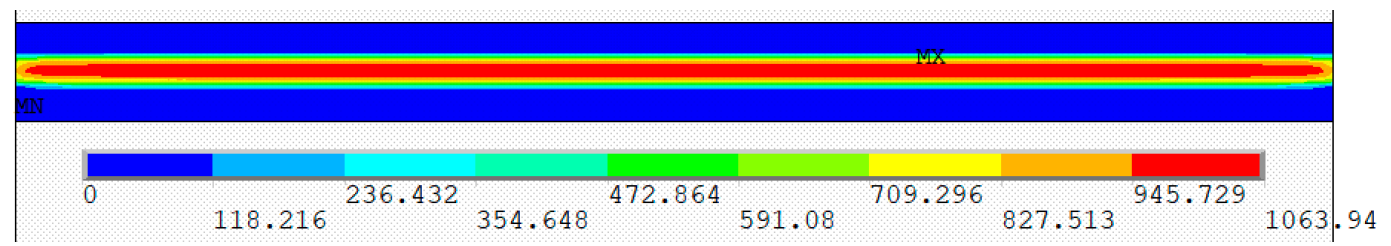

(a) Ideal gear

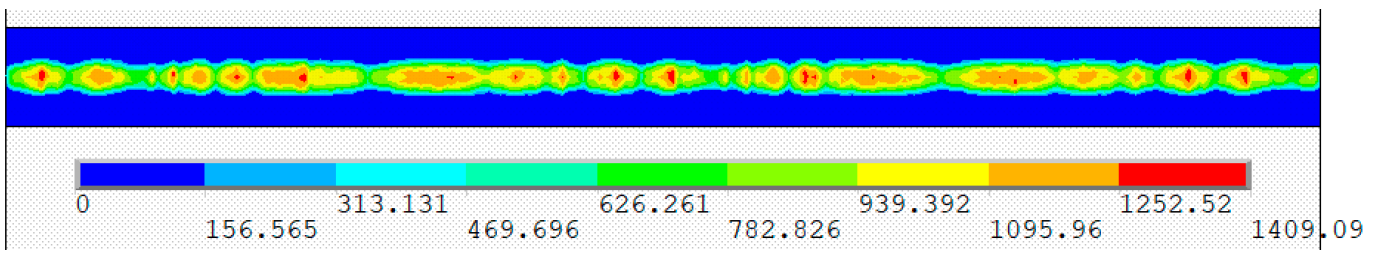

(b) Grade 2 precision gear

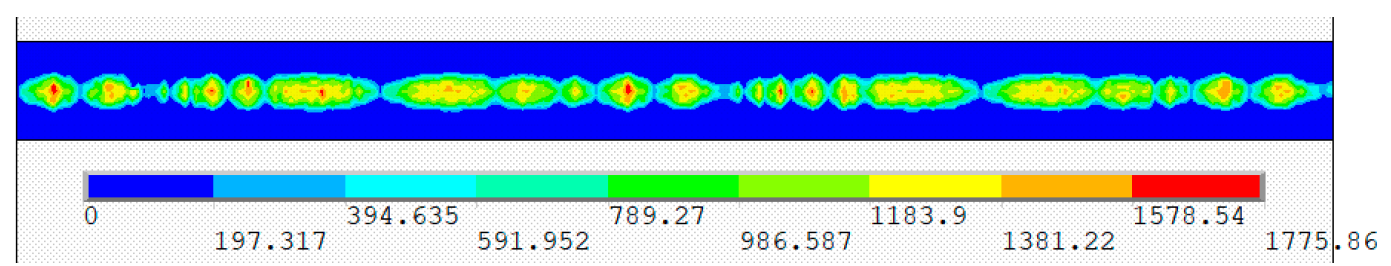

(c) Grade 4 precision gear

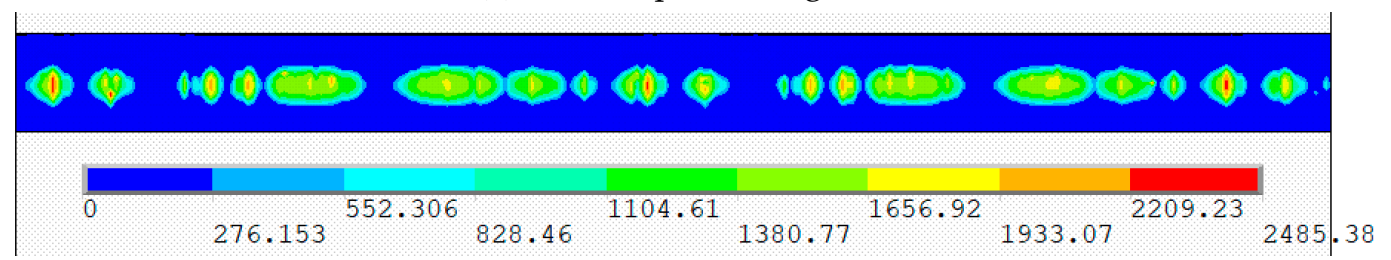

(d) Grade 6 precision gear

Figure 14. The TSCS nephograms of different precision grades of gears.

In this paper, the FEM contact analysis is conducted under different torques for different precision grades of gears, and the results of the maximum TSCS are compared as shown in Table 6 and Figure 15. It can be seen that the influence of TPD on the TSCS is very large, and the difference between the maximum TSCS corresponding to the different precision grades is large. At the same time, it is found that with the increase in applied load, the ratio of the maximum TSCS of each precision grade gear to the ideal gear gradually decreases.

Table 6. The results of the maximum TSCS under different torques. Unit: MPa.

\begin{tabular}{|c|c|c|c|c|c|c|c|c|}
\hline \multirow{2}{*}{$\begin{array}{c}\text { Precision } \\
\text { Grades }\end{array}$} & \multicolumn{8}{|c|}{ Torques $(\mathrm{N} \cdot \mathrm{m})$} \\
\hline & 8 & $\begin{array}{l}\text { Comparison with } \\
\text { Ideal Gears }\end{array}$ & 10 & $\begin{array}{l}\text { Comparison with } \\
\text { Ideal Gears }\end{array}$ & 12 & $\begin{array}{l}\text { Comparison with } \\
\text { Ideal Gears }\end{array}$ & 14 & $\begin{array}{l}\text { Comparison with } \\
\text { Ideal Gears }\end{array}$ \\
\hline Ideal & 937.19 & - & 1063.94 & - & 1166.77 & - & 1260.01 & - \\
\hline 2 & 1270.99 & $35.62 \%$ & 1409.09 & $32.44 \%$ & 1527.70 & $30.93 \%$ & 1627.02 & $29.13 \%$ \\
\hline 4 & 1635.07 & $74.47 \%$ & 1775.86 & $66.91 \%$ & 1902.75 & $63.08 \%$ & 2015.56 & $59.96 \%$ \\
\hline 6 & 2294.29 & $144.81 \%$ & 2485.38 & $133.60 \%$ & 2627.90 & $125.23 \%$ & 2770.99 & $119.91 \%$ \\
\hline
\end{tabular}




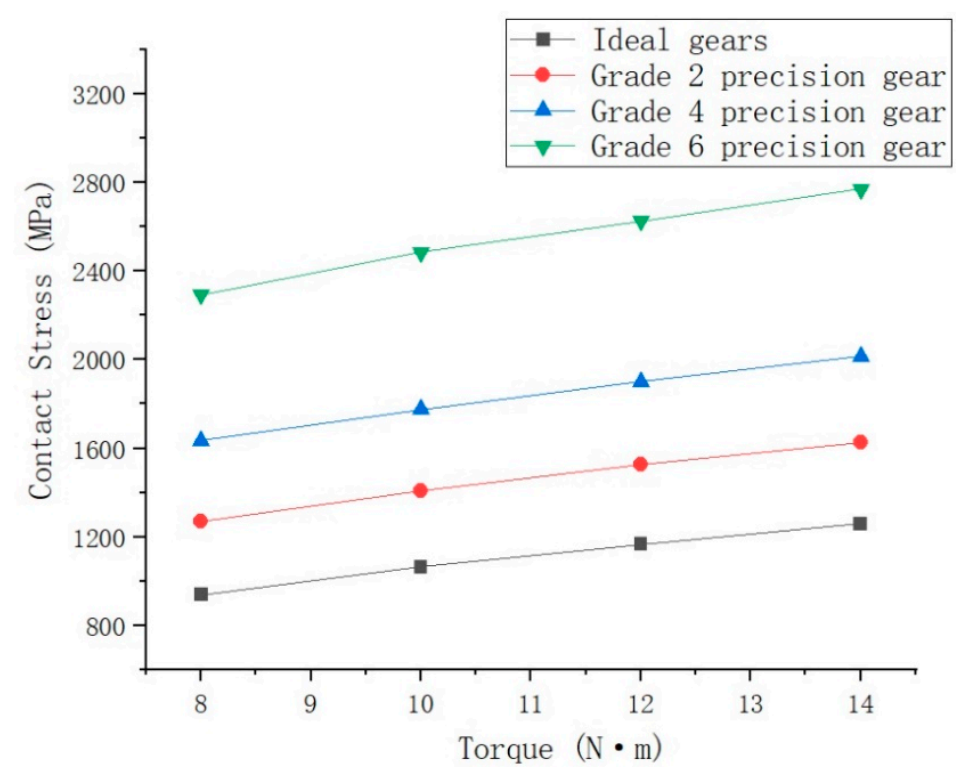

Figure 15. The results of the maximum TSCS under different torques.

\subsection{TSCS Analysis of Gear with ME}

In this paper, the ME is divided into two directions, and the ME in all directions can be decomposed into these two directions. As shown in Figure 16, point $A$ and point $C$ are the absolute center points of the two engaged gears. When the two gears are in the ideal engaged state, a $3 \mathrm{D}$ rectangular coordinate system is established with point $A$ as the origin, where the $A C$ direction is the $X$ axis direction, the $A B$ direction is the $\mathrm{Y}$ axis direction (which is the axial direction of gear 1), the $\mathrm{Z}$ axis direction is the radial direction of gear 1 , plane $\mathrm{V}$ is the plane composed of the $\mathrm{Y}$ axis and $\mathrm{Z}$ axis, and plane $\mathrm{S}$ is the plane composed of the $X$ axis and $Y$ axis. Then, the first kind of $M E$ is the rotation error around the $Z$ axis in the $\mathrm{S}$ plane, and the amount of meshing error is $\angle \mathrm{BAB}_{2}$, which is $<a$, and the second kind of $\mathrm{ME}$ is the rotation error around the $\mathrm{X}$ axis in the $\mathrm{V}$ plane, and the amount of $\mathrm{ME}$ is $<\mathrm{BAB}_{1}$, which is $<b$.

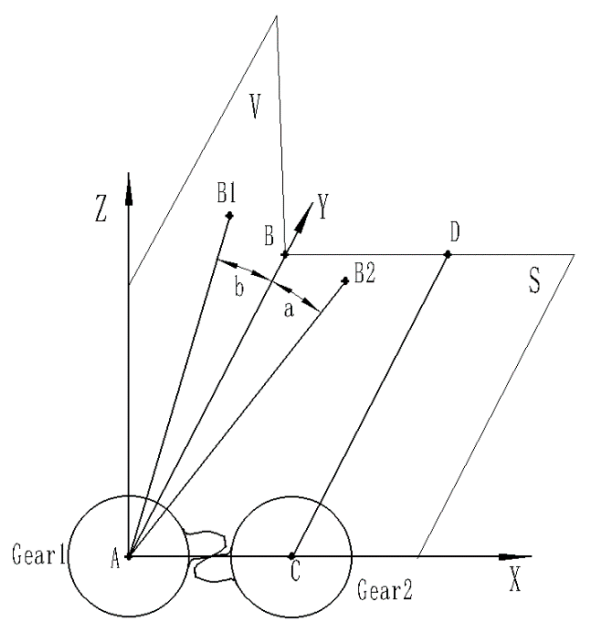

Figure 16. Definitions of meshing errors (ME).

According to the actual measurement data from the gear factory, most of the range of the $<a$ value is $0.1-0.7^{\circ}$, and most of the range of the $<b$ value is $0.02-0.15^{\circ}$. Taking the counterclockwise rotation direction as the positive direction, selecting $0.2^{\circ}, 0.4^{\circ}$ and $0.6^{\circ}$ for $<a$ respectively, and conducting the gear FEM contact analysis under the applied torque of $10 \mathrm{~N} \cdot \mathrm{m}$, the analysis results are shown in 
Figure 17. Then, selecting $-0.04^{\circ},-0.08^{\circ}$ and $-0.12^{\circ}$ for $<b$, respectively, and conducting the gear FEM contact analysis under the applied torque of $10 \mathrm{~N} \cdot \mathrm{m}$, the analysis results are shown in Figure 18.

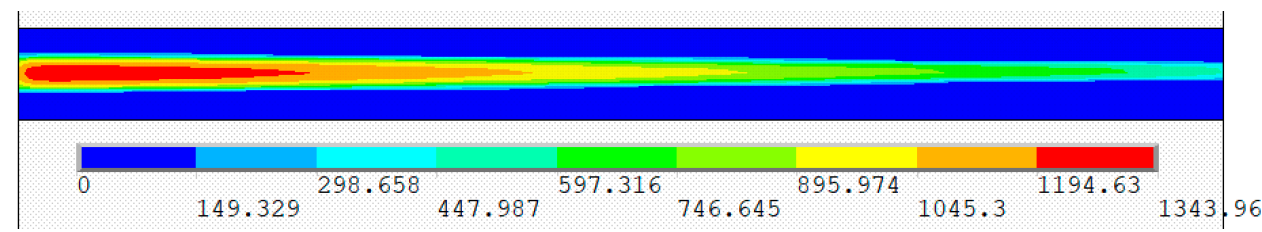

(a) $<a=0.2^{\circ}$

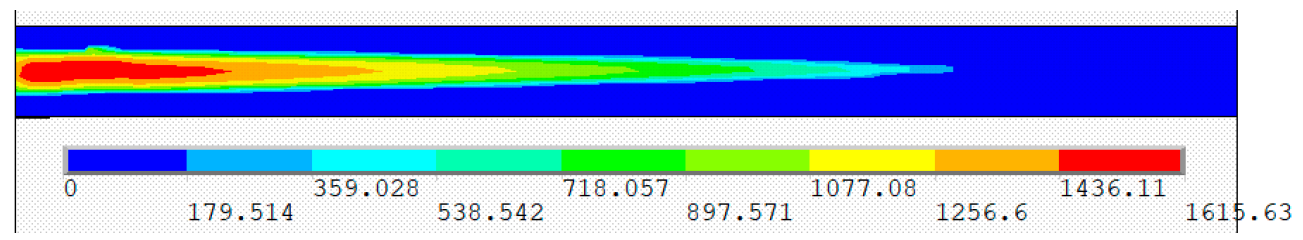

(b) $<a=0.4^{\circ}$

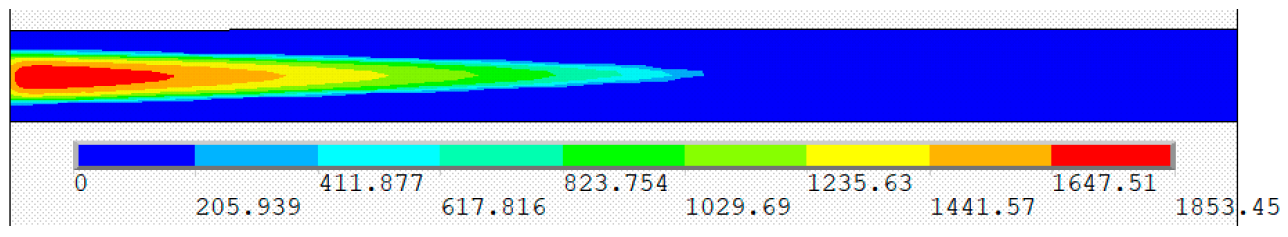

(c) $<a=0.6^{\circ}$

Figure 17. The TSCS nephograms of $<a=0.2^{\circ},<a=0.4^{\circ}$ and $<a=0.6^{\circ}$.

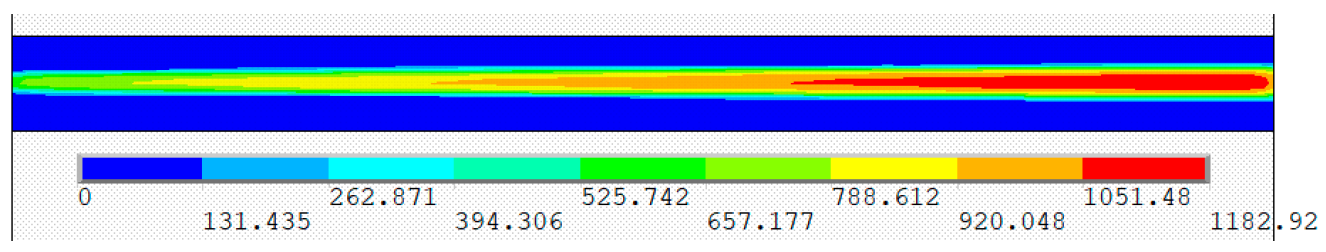

(a) $<b=-0.04^{\circ}$

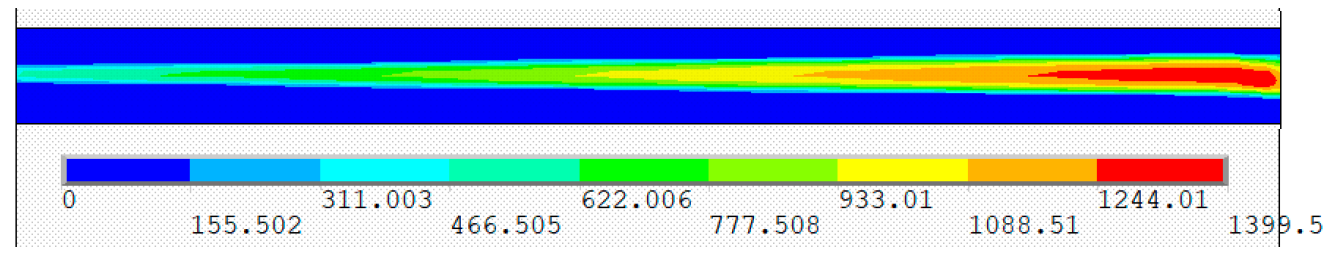

(b) $<b=-0.08^{\circ}$

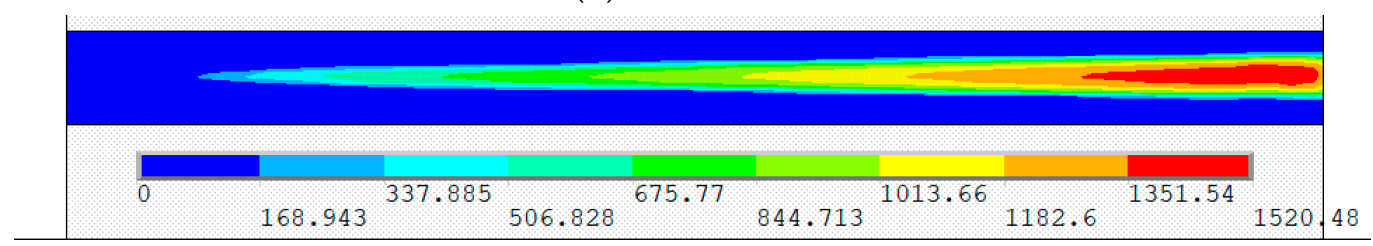

(c) $<b=-0.12^{\circ}$

Figure 18. The TSCS nephograms of $<b=-0.04^{\circ},<b=-0.08^{\circ}$ and $<b=-0.12^{\circ}$.

In Figure 17, from Figure 17a to Figure 17c are shown the TSCS nephograms of $<a=0.2^{\circ},<a=0.4^{\circ}$ and $<a=0.6^{\circ}$. It can be seen that the TSCS with an ME of $<a$ is concentrated on the left side of the tooth surface, and with the increase in $<a$ value, the gradient of the local TSCS increases gradually, and the maximum TSCS also increases accordingly. 
In a similar situation, as can be seen from Figure 18, from Figure 18a to Figure 18c are the TSCS nephograms of $<b=-0.04^{\circ},<b=-0.08^{\circ}$ and $<b=-0.12^{\circ}$. It can be seen that the TSCS with the ME of $<b$ is concentrated on the right side of the tooth surface, and with the increase in $<b$ value, the gradient of the local TSCS increases gradually, and the maximum TSCS also increases accordingly.

In addition, it can be seen from the figures that the TSCS of gears with an ME of $<a$ is concentrated on the left side of the tooth surface, while the TSCS of gears with an ME of $<b$ is concentrated on the right side of the tooth surface. There should be some interaction between the two kinds of ME, which needs further study.

In this paper, the FEM contact analysis is conducted under different torques for gears with different $\mathrm{ME}$, and the results of the maximum TSCS are compared as shown in Table 7 and Figure 19. It can be seen that the influence of ME on the TSCS is very large, and the difference between the maximum TSCS corresponding to the different ME values is large. Within the set range for the ME value, the influence degree of $<a$ is relatively greater. At the same time, it is found that with the increase in applied load, the ratio of the maximum TSCS of each gear a different ME to the ideal gear gradually decreases.

Table 7. The results of the maximum TSCS under different torques. Unit: MPa.

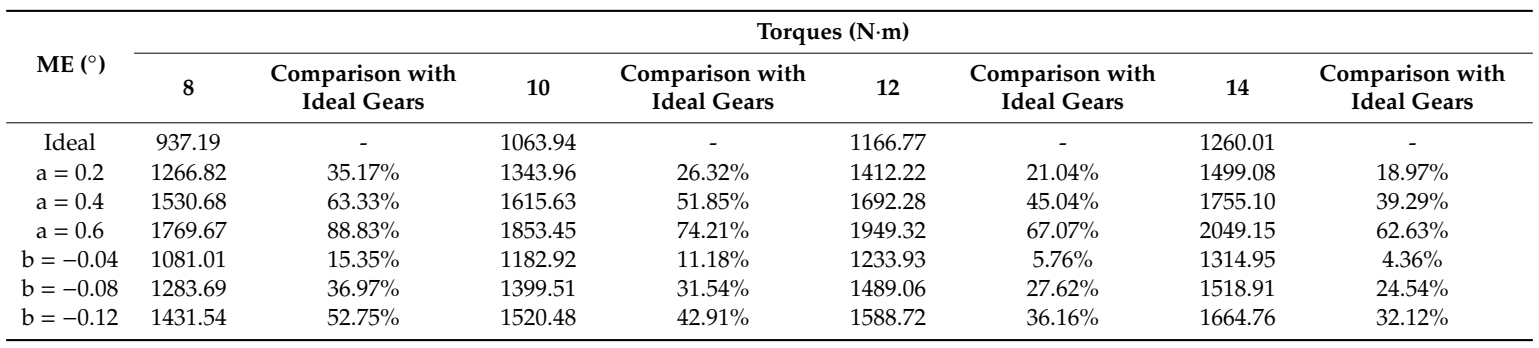

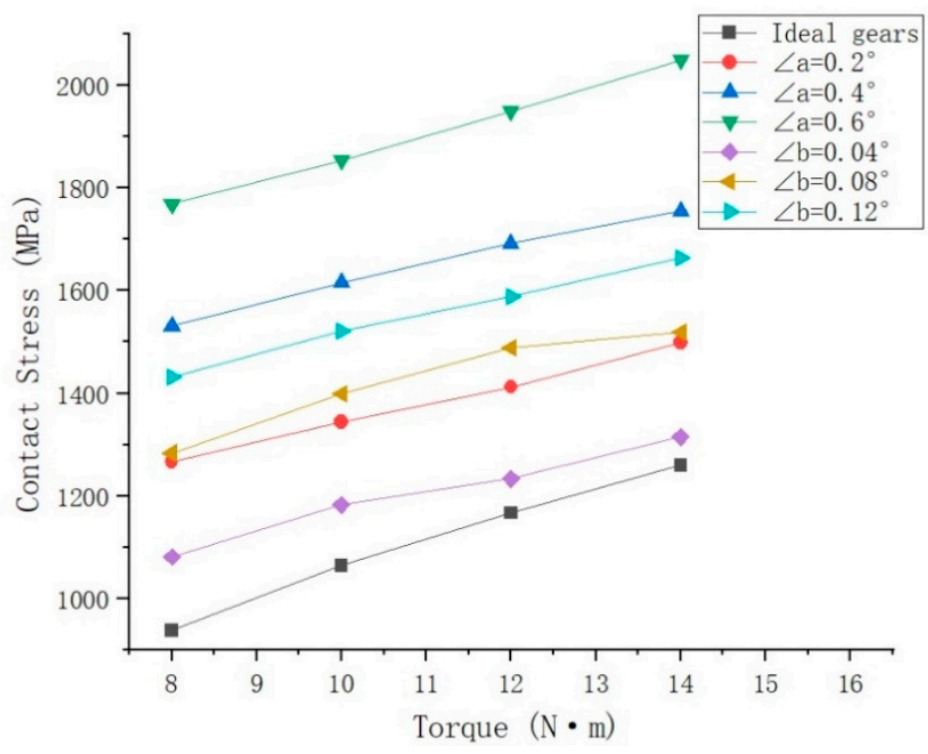

Figure 19. The results of the maximum TSCS under different torques.

\subsection{TSCS Analysis of Gear with LCM}

The purpose of the LCM is to ensure that when the gears are at the maximum inclination, the teeth engaged with each other do not have an edge point contact (tangent but not intersecting), so as to reduce edge contact.

It should be admitted that there is a certain load concentration phenomenon on the tooth surface with LCM, so the LCM should meet the most basic requirements as follows: first, when the gear tooth has the maximum inclination, the gear tooth shall not have the edge embedding phenomenon; second, when the gear tooth does not incline or has a certain inclination, the gear tooth shall have the minimum 
load concentration, that is, the lead crowning radius should be the largest (the LCM quantity is the smallest).

According to the ISO standard [4], the LCM mainly considers the ME of the original gear, and the formula is as follows:

$$
C=0.5 \times F_{\beta x c v}
$$

where $F_{\beta x c v}$ is the original equivalent misalignment for the determination of the crowning height. According to the range of ME set in this paper, the LCM quantities are taken as $3.5 \mu \mathrm{m}, 7 \mu \mathrm{m}$ and $10.5 \mu \mathrm{m}$, respectively, for the FEM contact analysis.

Figure 20 shows the LCM of the tooth surface, where $a$ is the tooth width, $l=0.5 \times a, C$ is the LCM quantity, and the lead crowning radius is:

$$
R=\frac{l^{2}}{2 \times C}
$$

Adjust the tooth surface nodes to input the LCM to the FEM model. Then, the calculation formula of the modification quantity of node $i$ is:

$$
C_{i}=C \times\left(\frac{l_{i}}{l}\right)^{2}
$$

where $l_{i}$ is the distance from the node numbered $i$ to the center line of the tooth width.

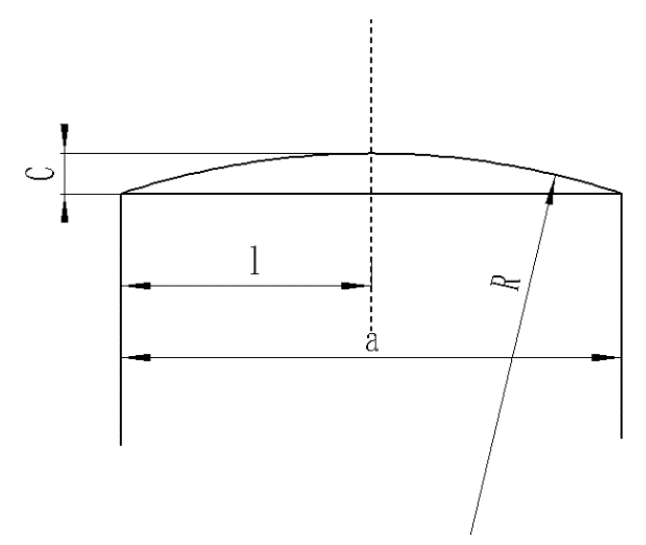

Figure 20. The lead crowning modifications (LCM) of the tooth surface.

In this paper, selecting $3.5 \mu \mathrm{m}, 7 \mu \mathrm{m}$ and $10.5 \mu \mathrm{m}$ for the LCM quantities, respectively, and conducting the gear FEM contact analysis under the applied torque of $10 \mathrm{~N} \cdot \mathrm{m}$, the analysis results are shown in Figure 21.

In Figure 21, from Figure 21a to Figure 21c are shown the TSCS nephograms of $C=3.5 \mu \mathrm{m}$, $C=7 \mu \mathrm{m}$ and $C=10.5 \mu \mathrm{m}$. It can be seen that the TSCS with LCM presents stress the concentration phenomenon in the center of the tooth surface, and with the increase in LCM quantity, the gradient of the local TSCS increases gradually, and the maximum TSCS also increases accordingly.

In this paper, the FEM contact analysis is conducted under different torques for gears with different LCM quantities, and the results of the maximum TSCS are compared as shown in Table 8 and Figure 22. It can be seen that the influence of LCM on the TSCS is very large. At the same time, it is found that with the increase in applied load, the ratio of the maximum TSCS of each gear with different ME to the ideal gear gradually decreases. 


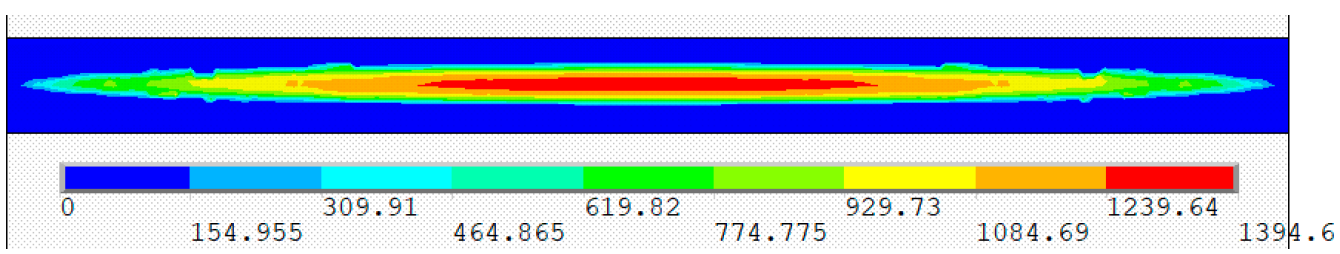

(a) $C=3.5 \mu \mathrm{m}$

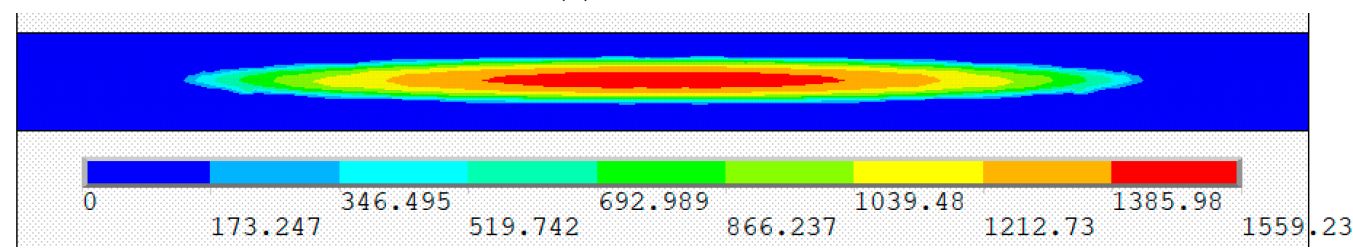

(b) $C=7.0 \mu \mathrm{m}$

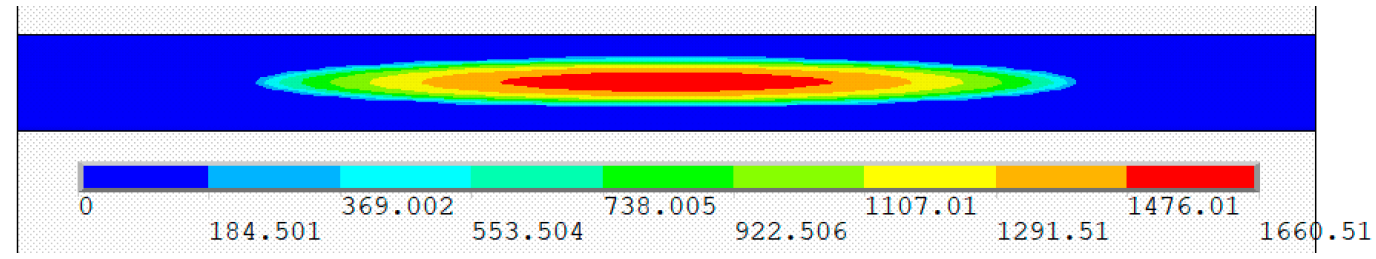

(c) $C=10.5 \mu \mathrm{m}$

Figure 21. The TSCS nephograms of $C=3.5 \mu \mathrm{m}, C=7 \mu \mathrm{m}$ and $C=10.5 \mu \mathrm{m}$.

Table 8. The results of the maximum TSCS under different torques. Unit: MPa.

\begin{tabular}{|c|c|c|c|c|c|c|c|c|}
\hline \multirow{2}{*}{$\begin{array}{c}\text { LCM } \\
\text { Quantity }(\mu \mathrm{m})\end{array}$} & \multicolumn{8}{|c|}{ Torques $(\mathbf{N} \cdot \mathbf{m})$} \\
\hline & 8 & $\begin{array}{l}\text { Comparison with } \\
\text { Ideal Gears }\end{array}$ & 10 & $\begin{array}{l}\text { Comparison with } \\
\text { Ideal Gears }\end{array}$ & 12 & $\begin{array}{l}\text { Comparison with } \\
\text { Ideal Gears }\end{array}$ & 14 & $\begin{array}{l}\text { Comparison with } \\
\text { Ideal Gears }\end{array}$ \\
\hline Ideal & 937.19 & - & 1063.94 & - & 1166.77 & - & 1260.01 & - \\
\hline 2 & 1285.64 & $37.18 \%$ & 1394.60 & $31.08 \%$ & 1495.83 & $28.20 \%$ & 1587.48 & $25.99 \%$ \\
\hline 4 & 1444.08 & $54.09 \%$ & 1559.23 & $46.55 \%$ & 1668.85 & $43.03 \%$ & 1754.07 & $39.21 \%$ \\
\hline 6 & 1541.64 & $64.50 \%$ & 1660.51 & $56.07 \%$ & 1768.54 & $51.58 \%$ & 1851.27 & $46.93 \%$ \\
\hline
\end{tabular}

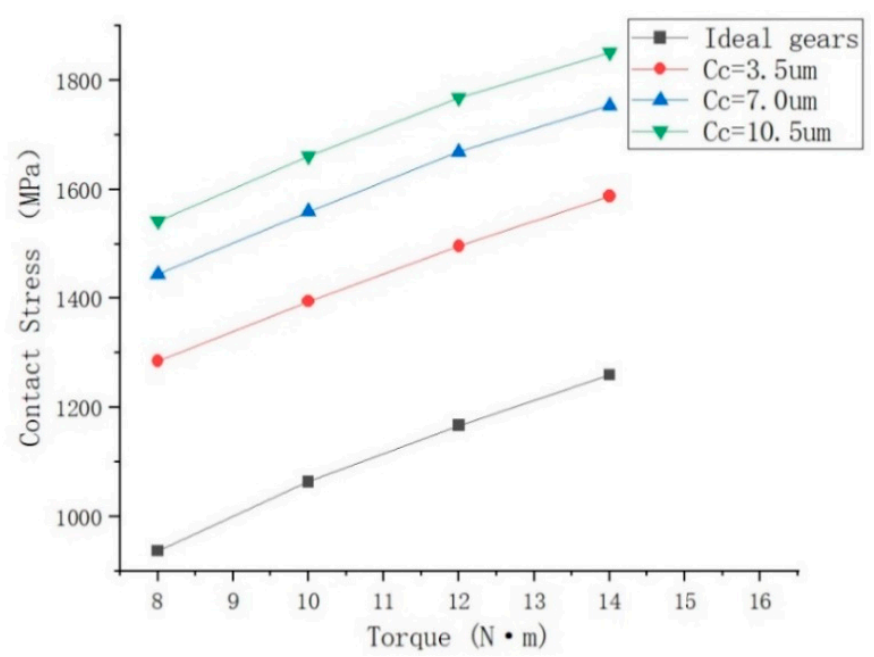

Figure 22. The results of the maximum TSCS under different torques.

The object of the above FEM contact analysis results is a pair of engaged teeth with only LCM and no ME. However, as we all know, in the actual gear engagement process, this must be accompanied by ME and TPD, and the lead crowning machining is also an essential process of gear machining. This is 
because the LCM can effectively reduce the stress concentration at the edge point caused by the ME and the TPD; therefore, there must be an interaction between these factors, which needs further study.

\section{Analysis of the Influence of TPD, ME and LCM on TSCS by TM}

According to the content of the third chapter, it can be found that when the TPD, ME and LCM exist separately, the influence on the TSCS is relatively large. However, when the above three factors exist in the gear at the same time, due to the interaction between the factors, the influence degree on the contact stress is not a simple superposition.

This chapter mainly studies the interaction between these three factors, and the influence degree of each factor on the TSCS when the above three factors exist at the same time. As a powerful tool, the Taguchi method can effectively study the above problems, and its steps are shown in Figure 23.

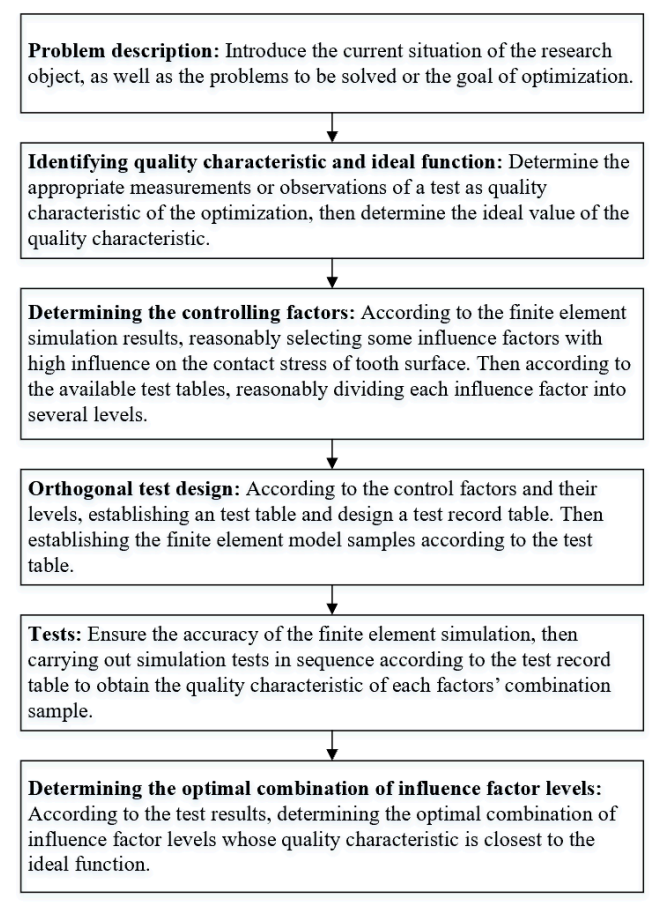

Figure 23. The steps of the Taguchi method (TM).

\subsection{Preparations before the Tests}

Problem description: When there are three influence factors of TPD, ME and LCM at the same time for a certain type of gear, one must research the influence degree of each factor on the TSCS and the interaction between them, and then determine the optimal combination of factor levels, so as to reduce the TSCS as much as possible.

Quality characteristic and ideal function: Take the maximum TSCS as the quality characteristic. The smaller the maximum TSCS is, the better.

Control factors: The above three factors are the control factors of the Taguchi method. For the TPD, it is divided into three levels (grade 2 precision, grade 4 precision and grade 6 precision). For the ME, $<a$ is divided into three levels $\left(0.2^{\circ}, 0.4^{\circ}\right.$ and $\left.0.6^{\circ}\right)$, and $<b$ is divided into three levels $\left(-0.04^{\circ},-0.08^{\circ}\right.$ and $\left.-0.12^{\circ}\right)$. For the LCM, it is divided into three levels $(C=3.5 \mu \mathrm{m}, C=7 \mu \mathrm{m}$ and $C=10.5 \mu \mathrm{m})$. The control factor levels are shown in Table 9. 
Table 9. The levels of control factors.

\begin{tabular}{ccccc}
\hline Control Factors & TPD & $<a$ & $<b$ & LCM \\
\hline Level 1 & Grade 2 & $0.2^{\circ}$ & $-0.04^{\circ}$ & $3.5 \mu \mathrm{m}$ \\
Level 2 & Grade 4 & $0.4^{\circ}$ & $-0.08^{\circ}$ & $7 \mu \mathrm{m}$ \\
Level 3 & Grade 6 & $0.6^{\circ}$ & $-0.12^{\circ}$ & $10.5 \mu \mathrm{m}$ \\
\hline
\end{tabular}

Test design: According to Table 9, the next step is to establish an orthogonal test table to record the test data, and the corresponding FEM simulation model is established according to the orthogonal test table. In this paper, Minitab is used to generate the orthogonal test table. There are two kinds of test tables with four factors and three levels. One has nine groups of tests, and the other has 27 groups of tests. Because we want not only to get the optimal combination of the factor levels, but also to research the interaction between various factors, 27 groups of tests are selected. The test table is shown in Table 10 .

Table 10. The orthogonal test table.

\begin{tabular}{ccccc}
\hline Serial Number & Tooth Profile Precision Grade & $<\boldsymbol{b}\left({ }^{\circ}\right)$ & $<\boldsymbol{a}\left({ }^{\circ}\right)$ & Lead Crowning $(\boldsymbol{\mu m})$ \\
\hline 1 & Grade 2 & -0.04 & 0.2 & 3.5 \\
2 & Grade 2 & -0.04 & 0.4 & 7.0 \\
3 & Grade 2 & -0.04 & 0.6 & 10.5 \\
4 & Grade 4 & -0.08 & 0.2 & 3.5 \\
5 & Grade 4 & -0.08 & 0.4 & 7.0 \\
6 & Grade 4 & -0.08 & 0.6 & 10.5 \\
7 & Grade 6 & -0.12 & 0.2 & 3.5 \\
8 & Grade 6 & -0.12 & 0.4 & 7.0 \\
9 & Grade 6 & -0.12 & 0.6 & 7.5 \\
10 & Grade 4 & -0.12 & 0.2 & 10.5 \\
11 & Grade 4 & -0.12 & 0.4 & 3.5 \\
12 & Grade 4 & -0.12 & 0.6 & 7.0 \\
13 & Grade 6 & -0.04 & 0.2 & 10.5 \\
14 & Grade 6 & -0.04 & 0.4 & 3.5 \\
15 & Grade 6 & -0.04 & 0.6 & 7.0 \\
16 & Grade 2 & -0.08 & 0.2 & 10.5 \\
17 & Grade 2 & -0.08 & 0.4 & 3.5 \\
18 & Grade 2 & -0.08 & 0.6 & 10.5 \\
19 & Grade 6 & -0.08 & 0.2 & 3.5 \\
20 & Grade 6 & -0.08 & 0.4 & 7.0 \\
21 & Grade 6 & -0.08 & 0.6 & 10.5 \\
22 & Grade 2 & -0.12 & 0.2 & 3.5 \\
23 & Grade 2 & -0.12 & 0.4 & 7.0 \\
24 & Grade 2 & -0.12 & 0.6 & 3.5 \\
25 & Grade 4 & -0.04 & 0.2 & \\
26 & Grade 4 & -0.04 & 0.4 & 0.5 \\
27 & Grade 4 & -0.04 & 0.6 & \\
\hline
\end{tabular}

\subsection{Analysis of FEM Simulation Results}

According to Table 9, 27 FEM simulation models with different factor level combinations are established and solved.

Figure 24 is the TSCS nephogram of the first FEM model in Table 10, and compared with the TSCS nephogram with only one single influence factor, it has the characteristics of irregularity of TPD, an edge stress concentration of ME and a central stress concentration of LCM. Table 11 shows the results of 27 FEM simulation tests. 


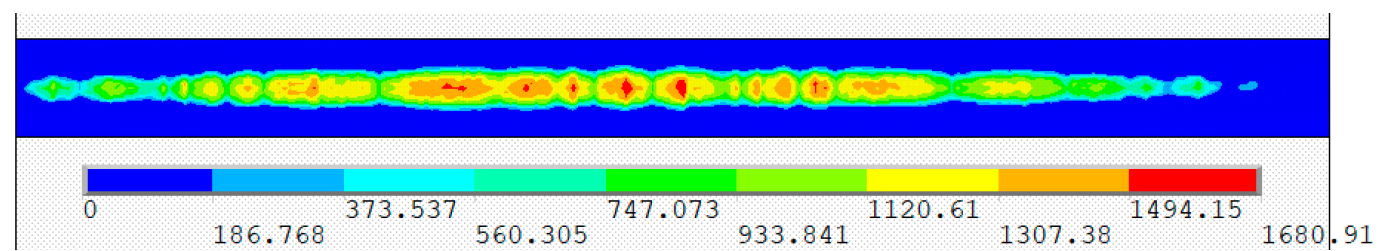

Figure 24. The TSCS nephogram of the first FEM model.

Table 11. The maximum TSCS of 27 FEM simulation tests.

\begin{tabular}{cccccc}
\hline Serial Number & Maximum TSCS (MPa) & Serial Number & Maximum TSCS (MPa) & Serial Number & Maximum TSCS (MPa) \\
\hline 1 & 1680.91 & 10 & 2272.12 & 19 & 3888.53 \\
2 & 1854.25 & 11 & 2459.15 & 20 & 3070.89 \\
3 & 1931.67 & 12 & 2135.32 & 22 & 3636.82 \\
4 & 2118.22 & 13 & 3719.14 & 23 & 1962.06 \\
5 & 2322.13 & 14 & 3819.85 & 24 & 1683.50 \\
6 & 2420.97 & 15 & 1907.33 & 26 & 2454.60 \\
7 & 3102.55 & 16 & 1999.51 & 27 & 27 \\
9 & 3753.72 & 18 & 1806.02 & & 2297.35 \\
\hline
\end{tabular}

Minitab (17.1.0, Minitab, LLC, State College, PA, USA) was used to analyze the test results. The Minitab response tables for signal to noise (SN) ratios and means are shown in Table 12. From the table, whether it is the SN ratios response table or the mean response table, it can be seen that the TPD has the greatest influence on the TSCS, followed by the LCM; the $<b$ and $<a$ are relatively much smaller.

Table 12. The Minitab response tables for signal to noise (SN) ratios and means.

\begin{tabular}{|c|c|c|c|c|c|c|c|c|}
\hline \multirow{2}{*}{ Level } & \multicolumn{2}{|c|}{ Tooth Profile Accuracy } & \multicolumn{2}{|c|}{$<b\left(^{\circ}\right)$} & \multicolumn{2}{|c|}{$<a\left({ }^{\circ}\right)$} & \multicolumn{2}{|c|}{ Lead Crowning $(\mu \mathrm{m})$} \\
\hline & SN Ratios & Means & SN Ratios & Means & SN Ratios & Means & SN Ratios & Means \\
\hline 1 & -65.34 & 1853 & -67.85 & 2574 & -67.83 & 2567 & -67.09 & 2334 \\
\hline 3 & -71.01 & 3565 & -67.81 & 2564 & -67.87 & 2574 & -68.45 & 2755 \\
\hline Delta & 5.66 & 1712 & 0.08 & 10 & 0.04 & 7 & 1.36 & 421 \\
\hline Rank & \multicolumn{2}{|c|}{1} & \multicolumn{2}{|c|}{3} & \multicolumn{2}{|c|}{4} & \multicolumn{2}{|c|}{2} \\
\hline
\end{tabular}

The main effects plots for SN ratios and means are shown in Figure 25. From the Figure 25a,b, within the set value range, it can be seen that the influence degree of TPD on the TSCS is much greater than that of LCM, and the influence degree of LCM is much greater than that of ME. The influence degree of the two kind of ME is very small, and the difference is not big. In addition, it can be seen that when the precision grade changes from 4 to 6 , it has a great influence on the TSCS; when changing from 2 to 4 , the influence degree is significantly reduced. Similarly, for the LCM, when the LCM quantity changes from $3.5 \mu \mathrm{m}$ to $7 \mu \mathrm{m}$, the influence degree is also slightly larger.

\subsection{The Interaction between TPD, ME and LCM}

The interaction between different factors can be obtained through Minitab. Figure 26 shows the interaction plot for means between the TPD and other factors. The nonparallel lines in the interaction plot indicate the interaction degree between the TPD and other factors. If the three lines are completely parallel, it means that there is no interaction between them; on the contrary, the more nonparallel the three lines, the greater the interaction degree between them. 


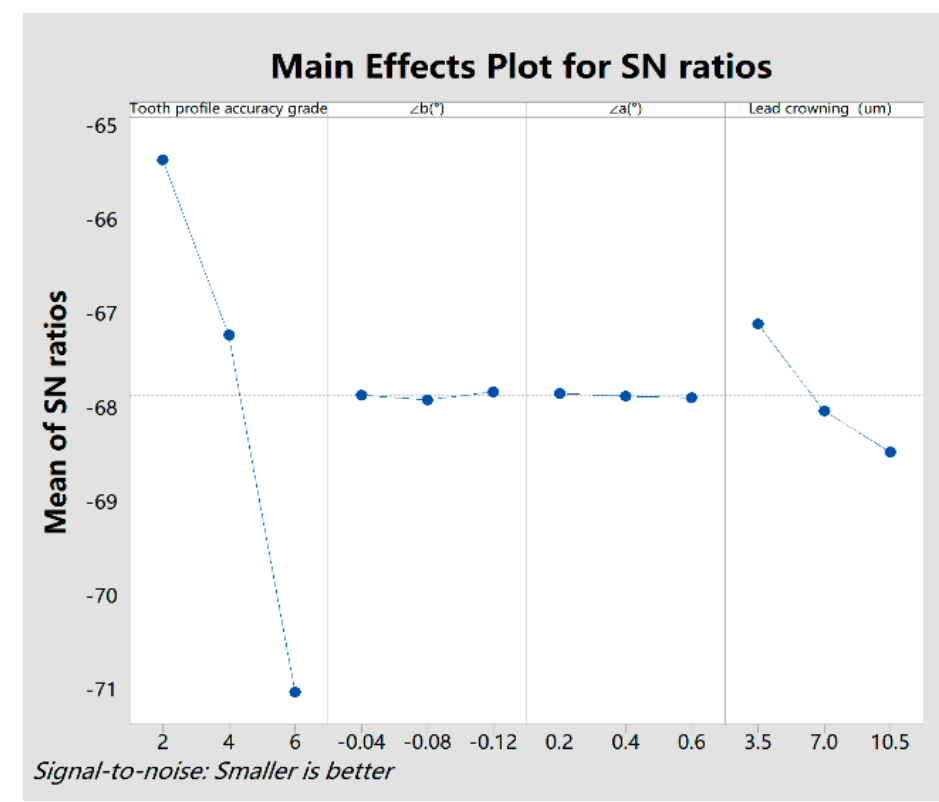

(a) The main effects plots for signal to noise (SN) ratios.

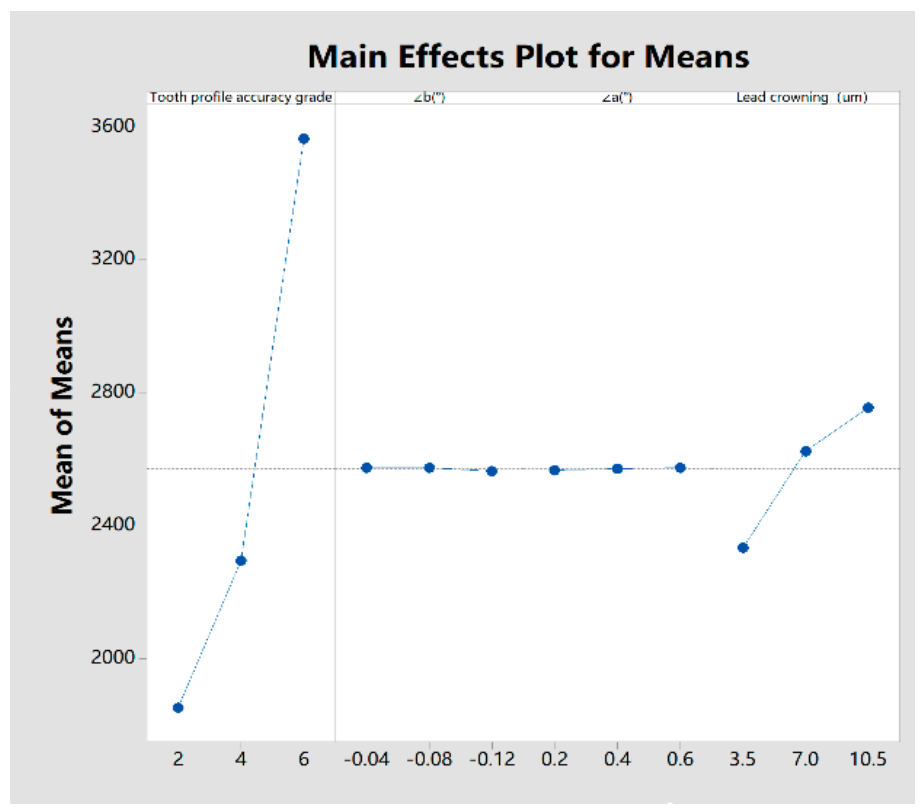

(b) The main effects plots for means.

Figure 25. The main effects plots for signal to noise (SN) ratios and means. 


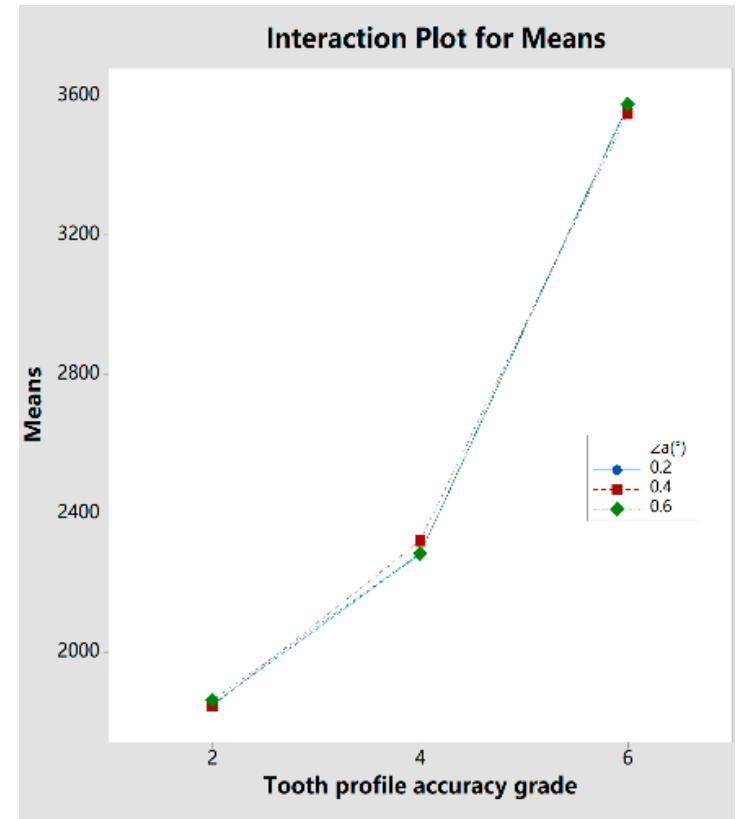

(a) The interaction plot for means between TPD and $<a$.

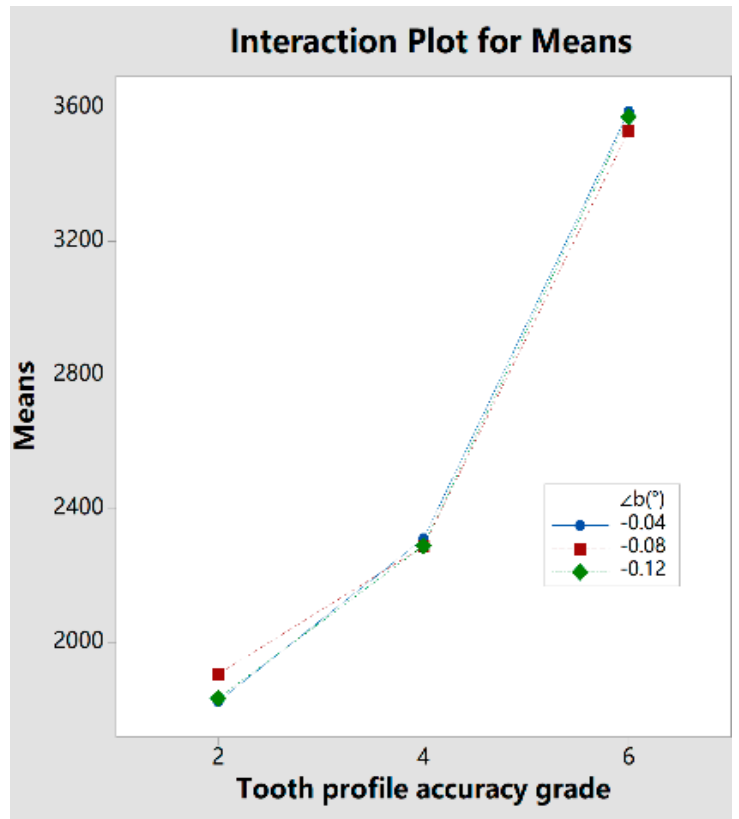

(b) The interaction plot for means between TPD and $<b$.

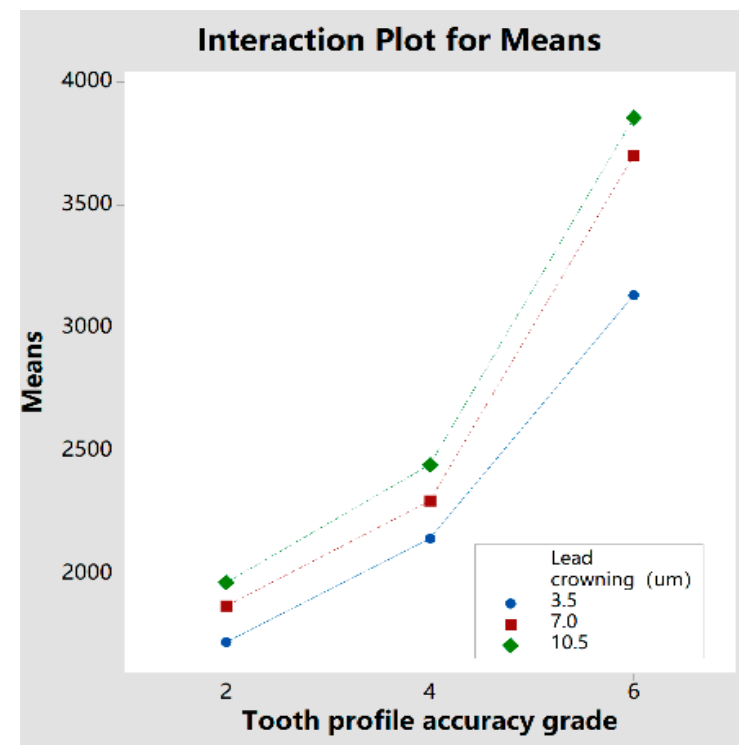

(c) The interaction plot for means between TPD and LCM.

Figure 26. The interaction plot for means between the TPD and other factors.

As can be seen from Figure 26a,b, there is basically no interaction between the TPD and the ME, and from Figure 26c, there is a certain interaction between the TPD and the LCM, but the interaction degree is not significant.

Figure 27a,b show the interaction plots for means between the LCM and the ME, and Figure 27c shows the interaction plot for means between $<a$ and $<b$. From Figure $27 a$, it can be seen that there is an obvious interaction between the LCM and the $<a$; in particular, when the $<a$ changes from $0.4^{\circ}$ to $0.6^{\circ}$, the interaction degree is more significant. From Figure $27 \mathrm{~b}$, it can be seen that there is also an obvious interaction between the LCM and the $<b$. Therefore, there is an obvious interaction between the LCM and the overall ME. From Figure 27c, it can be seen that the interaction degree between meshing errors $<a$ and $<b$ is very significant, even though the influence degree of these two kinds of ME on the TSCS is very small. 


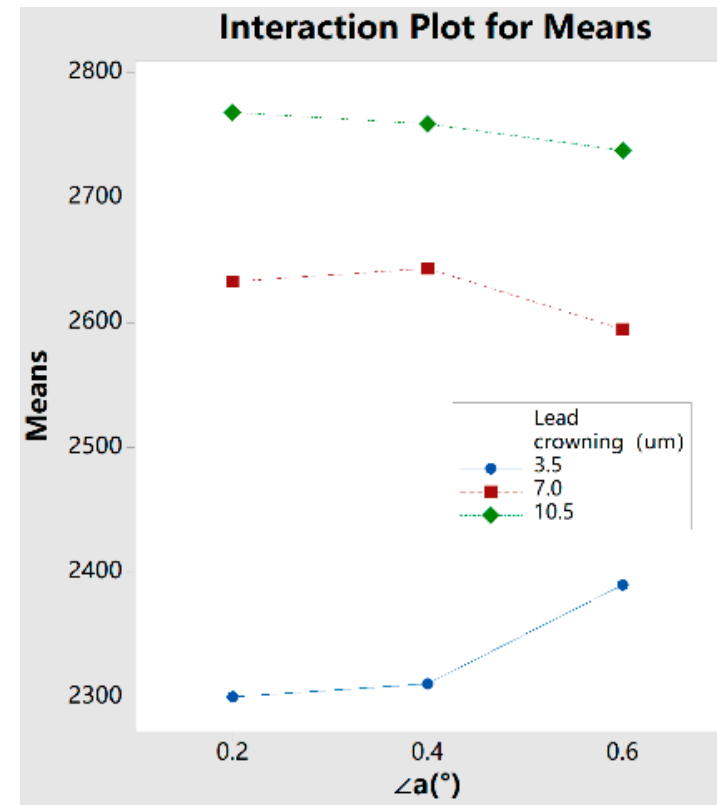

(a) The interaction plot for means between $<a$ and LCM.

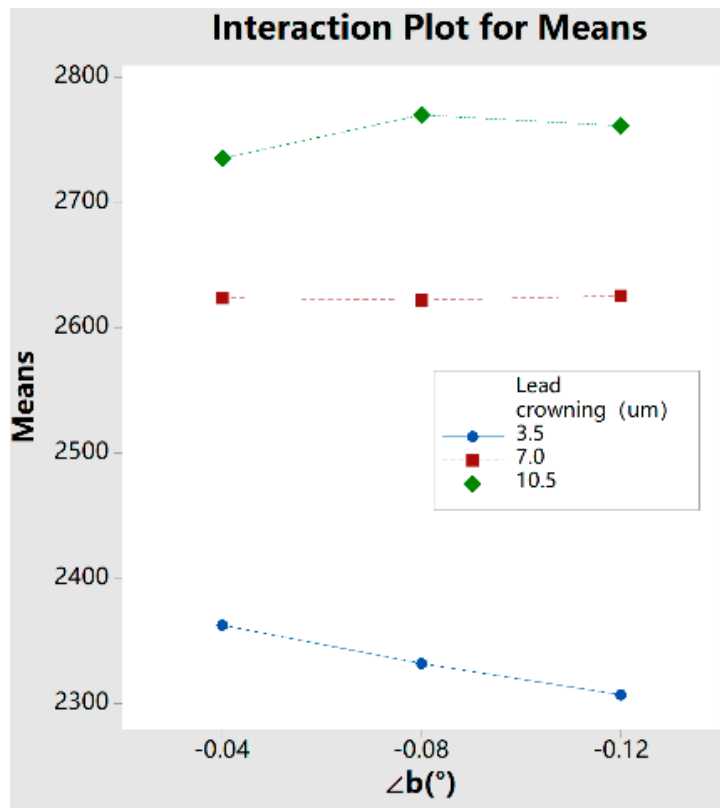

(b) The interaction plot for means between $<b$ and LCM.

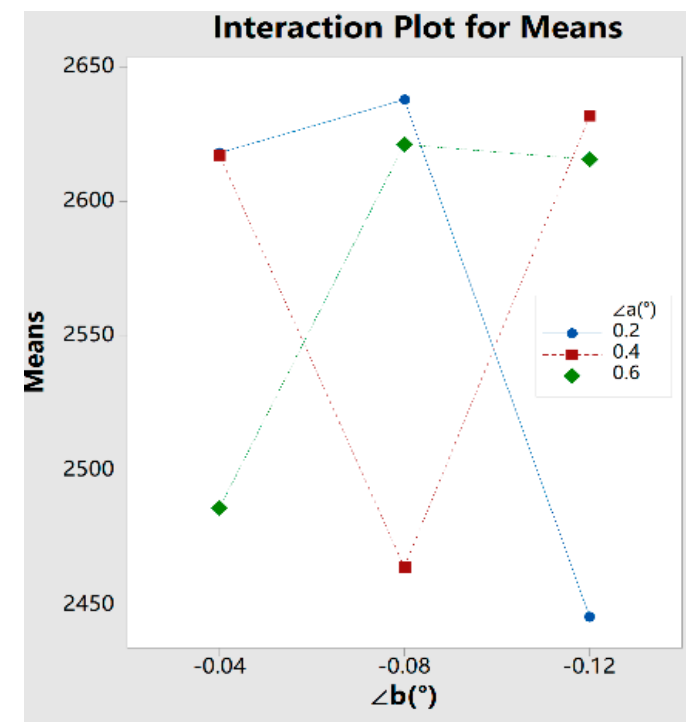

(c) The interaction plot for means between $<a$ and $<b$.

Figure 27. The interaction plot for means.

It can be known from the third chapter that when the $<a$ and $<b$ exist alone, they have a great influence on the TSCS. However, when all the influence factors exist, because of the obvious interaction between them, the influence degree of the $<a$ and $<b$ on the TSCS becomes very small.

In addition, in order to further verify the importance of LCM for the engaged gears with ME, two FEM simulation models are established. The two models have the same precision grade of TPD (grade $2),<a\left(0.2^{\circ}\right)$ and $<b\left(-0.04^{\circ}\right)$, but the first model does not have the LCM, and the second model has an LCM of $3.5 \mathrm{um}$. The TSCS analysis of the two models is carried out, and Figure 28a is the stress nephogram of the first model, while Figure $28 \mathrm{~b}$ is the stress nephogram of the second model. Through comparison, it can be found that the LCM can effectively alleviate the edge stress concentration caused by ME, and the maximum TSCS of the model with LCM is significantly smaller than that without LCM. This also demonstrates that there is an obvious interaction between LCM and ME. 


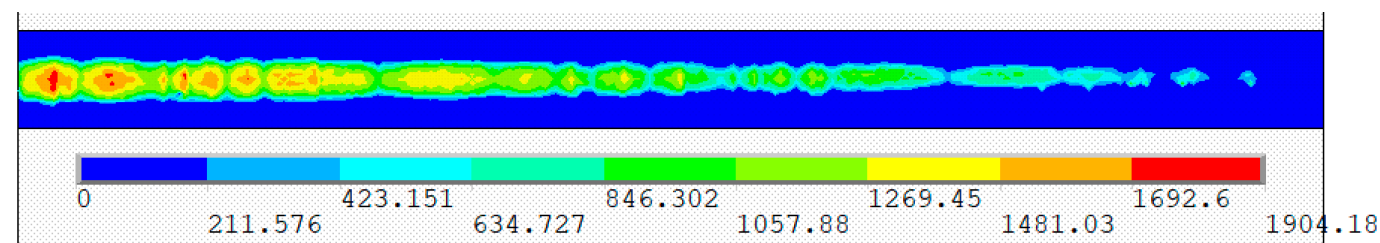

(a) The model without LCM.

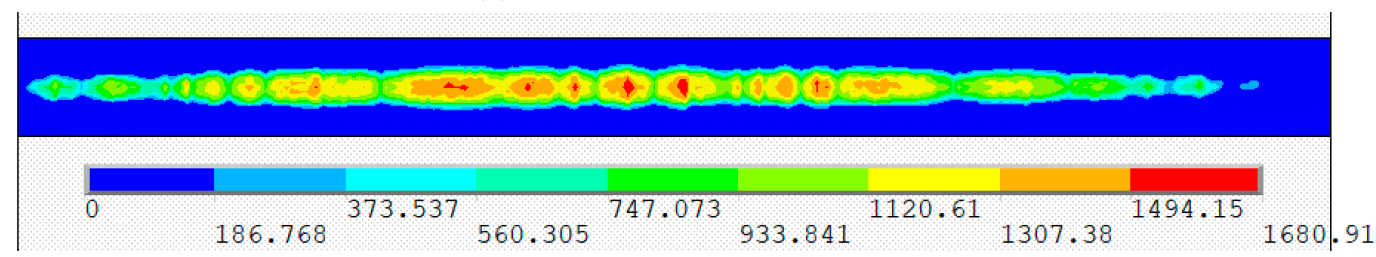

(b) The model with LCM.

Figure 28. The TSCS nephogram.

\subsection{Determining the Optimal Combination of Influence Factor Levels}

The maximum TSCS of each combination of factor levels can also be predicted by the Minitab. As shown in Figure 29, the approximate maximum TSCS corresponding to the combination of different factor levels can be obtained by inputting the level of each factor.

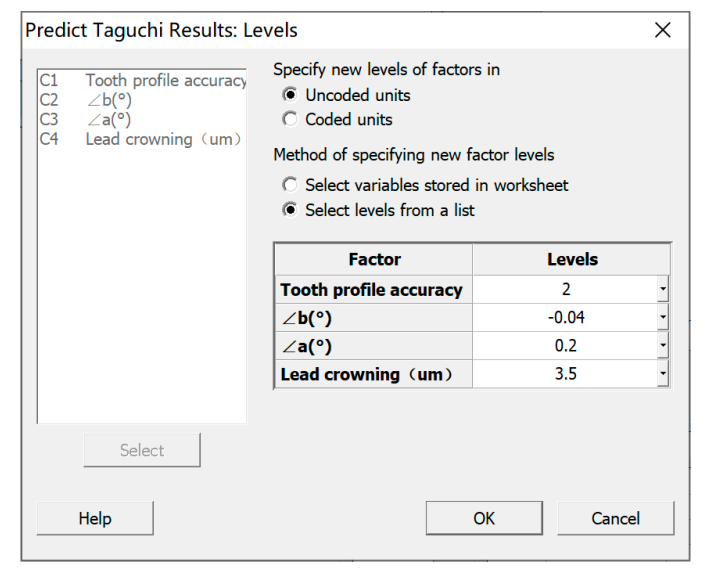

Figure 29. The Taguchi results are predicted by Minitab.

It can be seen from Figure 25 that the TPD grade is 2 and the LCM quantity is $3.5 \mu \mathrm{m}$ in the optimal combination of factor levels. Then, the prediction results of partial combinations are shown in Table 13. It can be seen from Table 13 that when the TPD grade is 2 and the LCM quantity is $3.5 \mu \mathrm{m}$, the ME has little effect on the maximum TSCS, and the maximum TSCS range is 1605.57-1622.67 MPa. Therefore, it is sufficient to control the $<a$ and $<b$ of ME within the specified range. However, in conclusion, it is determined that the optimal combination of factor levels is grade 2 for the TPD, $-0.12^{\circ}$ for the $<b, 0.2^{\circ}$ for the $<a$, and $3.5 \mu \mathrm{m}$ for the LCM quantity. 
Table 13. The prediction results of different combinations.

\begin{tabular}{ccccc}
\hline Table & $<\boldsymbol{b}\left({ }^{\circ}\right)$ & $<a\left(^{\circ}\right)$ & LCM $(\mu \mathrm{m})$ & TSCS $(\mathbf{M P a})$ \\
\hline & & 0.2 & & 1614.97 \\
& -0.04 & 0.4 & & 1618.91 \\
& & 0.6 & & 1622.06 \\
2 & 0.2 & 3.5 & 1615.59 \\
& & 0.4 & & 1619.53 \\
& & 0.6 & & 1622.67 \\
& & 0.2 & 1605.57 \\
& & 0.4 & & 1609.51 \\
& & 0.6 & & 1612.66 \\
\hline
\end{tabular}

\subsection{Comparative Analysis of Different Combinations of Factor Levels}

According to the original process requirements of precision gear manufacturing in a gear factory, the TPD, $<a,<b$ and LCM are required to be controlled at grade $4,0.4^{\circ},-0.08^{\circ}$ and $3.5 \mu \mathrm{m}$, respectively, and the maximum TSCS of the original combination of factor levels is $2062.00 \mathrm{MPa}$, which is $28.43 \%$ larger than the $1605.57 \mathrm{MPa}$ of the optimal combination.

In order to better show the influence of the TSCS on the gear fatigue life, according to the contact fatigue SN curve (Figure 30) and the corresponding curve equation (Equation (11)) provided by the gear factory, the gear fatigue life corresponding to different TSCS can be obtained.

$$
\lg \sigma=-0.0908 \lg \mathrm{N}+3.8767
$$

According to Equation (11), when the $\sigma=1605.57 \mathrm{MPa}$, the corresponding fatigue life $N=2.46 \times 10^{7}$, while when the maximum TSCS is $2062 \mathrm{MPa}$, the corresponding fatigue life $N=1.5 \times 10^{6}$. It can be found that the gear contact fatigue life of the optimal combination of factor levels is much longer than that of the original combination.

In addition, when the minimum fatigue life of the gear is required to be $1 \times 10^{7}$, the maximum acceptable TSCS is $1743 \mathrm{MPa}$, as calculated by Equation (11). Therefore, only when the TPD is grade 2 and the LCM is $3.5 \mu \mathrm{m}$ can the fatigue life meet the requirements. It also shows that the contact fatigue performance of the optimal combination of factor levels is better than that of the original combination.

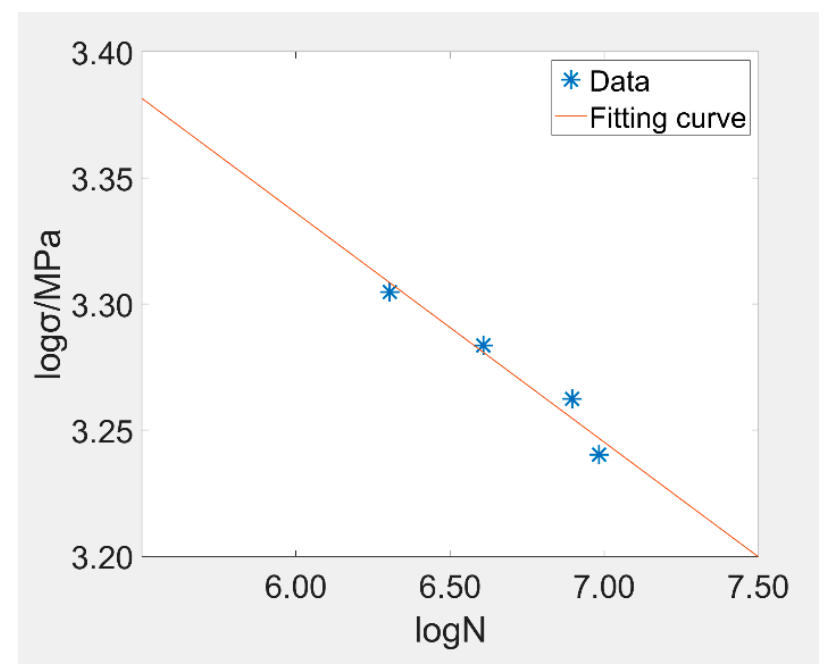

Figure 30. The contact fatigue SN curve. 


\section{Conclusions}

Based on the 3D-FEM and TM, this paper has analyzed the TSCS of spur gears with three different influence factors: TPD, ME and LCM. In particular, it has analyzed the interactions between PD, ME and LCM, and their influence degrees on the TSCS. Throughout the full paper, there are several conclusions that need to be summarized, as follows:

(1) In this paper, a 3D-FEM model of one pair of engaged teeth has been modeled and the mesh of the contact area has been refined by FEM software. In the model, the refined area mesh and the non-refined area mesh were connected by Multi-point constraint (MPC). At the same time, in order to save the time of the FEM solution on the premise of ensuring the accuracy of model analysis, the reasonable size of the refined area has been researched and confirmed;

(2) In this paper, the FEM contact models of gears have been established and solved according to the three influence factors of TPD, ME and LCM, respectively. It is found that when there is only one single influence factor, the influence factor has a great influence on the TSCS. Compared with the ideal gear, the maximum TSCS of the gear with TPD can reach 2.45 times of that of the ideal gear, the maximum TSCS of the gear with ME can reach 1.88 times of that of the ideal gear, and the maximum TSCS of the gear with LCM can reach 1.65 times of that of the ideal gear;

(3) In this paper, the Taguchi method has been used to research the influence degree of each factor on the TSCS when three factors exist at the same time. It is found that the TPD has the greatest influence on the TSCS, as the mean difference in TSCS between different grades of TPD can reach $1712 \mathrm{MPa}$. This is followed by the LCM, as the mean difference in TSCS between different LCM values can reach $421 \mathrm{MPa}$. The influence degree of $\mathrm{ME}$ is very limited, as the mean differences in TSCS value between different $<a$ and $<b$ are only $7 \mathrm{MPa}$ and $10 \mathrm{MPa}$, respectively;

(4) In this paper, the interactions between the influence factors have been researched, and it is found that the interactions between the TPD and other factors are not obvious, while the interactions between the LCM, $<a$ and $<b$ are very obvious, especially the interaction between the two kinds of ME. In addition, it has been verified that the LCM can effectively alleviate the phenomenon of the edge stress concentration of TSCS caused by ME. From Figure 28, it can be found that the maximum TSCS value of the gear with LCM is $11.73 \%$ less than that of the gear without LCM;

(5) According to the type of gear researched in this paper, through the TM, the optimal combination of control factor levels has been determined, as follows: grade 2 for the TPD, $-0.12^{\circ}$ for the $<b$, $0.2^{\circ}$ for the $<a$, and $3.5 \mu \mathrm{m}$ for the LCM quantity. The gear contact fatigue life of the optimal combination of factor levels is much longer than that of the original combination;

(6) For other types of gears and different influence factors, the research method and analysis process of this paper have certain reference value.

Author Contributions: Writing—original draft, Q.L.; Writing—review and editing, L.X. All authors have read and agreed to the published version of the manuscript.

Funding: This research was funded by the "Research on Reliability Theory and Method of Total Fatigue Life for Large and Complex Mechanical Structures" of Natural Science Foundation of China and Liaoning Province, grant number U1708255.

Conflicts of Interest: The authors declare no conflict of interest. 


\section{Abbreviations}

$\begin{array}{ll}\text { 3D } & \text { Three-dimensional } \\ \text { FEM } & \text { Finite element method } \\ \text { LCM } & \text { Lead crowning modifications } \\ \text { ME } & \text { Meshing errors } \\ \text { MPC } & \text { Multi-point constraint } \\ \text { TM } & \text { Taguchi method } \\ \text { TPD } & \text { Tooth profile deviations } \\ \text { TSCS } & \text { Tooth surface contact stress }\end{array}$

\section{References}

1. Wei, J.; Lv, C.; Sun, W.; Li, X.; Wang, Y. A study on optimum design method of gear transmission system for wind turbine. Int. J. Precis. Eng. Manufact. 2013, 14, 767-778. [CrossRef]

2. Li, M.; Xie, L.; Ding, L. Load sharing analysis and reliability prediction for planetary gear train of helicopter. Mechan. Mach. Theor. 2017, 115, 97-113. [CrossRef]

3. ISO 6336-2: 2019. Calculation of Load Capacity of Spur and Helical Gears-Part. 2: Calculation of Surface Durability (Pitting). Available online: https://www.iso.org/standard/63821.html (accessed on 6 September 2020).

4. ISO 6336-1. Calculation of Load Capacity of Spur and Helical Gears-Part. 1: Basic Principles, Introduction and General Influence Factors. Available online: https://www.iso.org/standard/63819.html (accessed on 6 September 2020).

5. Li, S. Finite element analyses for contact strength and bending strength of a pair of spur gears with machining errors, assembly errors and tooth modifications. Mech. Mach. Theory 2007, 42, 88-114. [CrossRef]

6. Sennba, M. Gear Errors and Strength; The Nikkan Kogyo Shimbun Press: Tokyo, Japan, 1974; pp. 70-148. (In Japanese)

7. Ottewill, J.; Neild, S.A.; Wilson, R. An investigation into the effect of tooth profile errors on gear rattle. J. Sound Vib. 2010, 329, 3495-3506. [CrossRef]

8. Ma, P.; Botman, M. Load Sharing in a Planetary Gear Stage in the Presence of Gear Errors and Misalignment. J. Mechan. Design 1985, 107, 4-10. [CrossRef]

9. Bodas, A.; Kahraman, A. Influence of carrier and gear manufacturing errors on the static planet load sharing behavior of planetary gear sets (gear unit design and applications). Japan Soc. Mechan. Engr. 2017. [CrossRef]

10. Miyoshi, Y.; Tobisawa, K.; Saiki, K. Composite analysis method of tooth contact load distribution of helical gear. In Proceedings of the ASME International Design Engrring Technical Conferences/Computers and Information in Engrring Conference, New York, NY, USA, 4-7 September 2007; pp. 173-180.

11. Wang, Q.B.; Hu, P.; Zhang, Y.; Wang, Y.; Pang, X.; Tong, C. A model to determine mesh characteristics in a gear pair with tooth profile error. Adv. Mechan. Engr. 2014, 6, 1-10. [CrossRef]

12. Lin, T.; He, Z. Analytical method for coupled transmission error of helical gear system with machining errors, assembly errors and tooth modifications. Mech. Syst. Signal. Process. 2017, 91, 167-182. [CrossRef]

13. Li, Q.; Xie, L.; Song, J.; Li, H.; Xu, G. Research Methods and Applications of Gear Manufacturing Process Optimization. Mathem. Probl. Eng. 2019, 2019, 1-17. [CrossRef]

14. Yu, B.S.; Liu, Y.Y. Improvement in phase purity and yield of hydrothermally synthesized smectite using Taguchi method. Appl. Clay Sci. 2018, 161, 103-109. [CrossRef]

15. Sun, B.; Xiao, J.; Li, Z.; Ma, B.; Zhang, L.; Huang, Y.; Bai, L. An analysis of soil detachment capacity under freeze-thaw conditions using the Taguchi method. Catena 2018, 162, 100-107. [CrossRef]

16. Mojtaba, F.; Abbas, N.; Sima, Z.; Mohammad, R.H. Optimization of H-shaped thin-walled energy absorber by Taguchi method and a new theoretical estimation for its energy absorption. Thin Wall. Struct. 2018, 131, 33-44.

17. Ji, D.; Wei, Z.; Mazzoni, S.; Mengarelli, M.; Rajoo, S.; Zhao, J.; Pou, J.; Romagnoli, A. Thermoelectric generation for waste heat recovery: Application of a system level design optimization approach via Taguchi method. Energy Convers. Manag. 2018, 172, 507-516. [CrossRef]

18. Shuting, L. Effects of misalignment error, tooth modifications and transmitted torque on tooth engagements of a pair of spur gears. Mechan. Machine Theory 2015, 83, 125-136. 
19. Hertz, H. On the contact of elastic solids. J. Reine Angew Math. 1882, 92, 156-171.

20. ISO 1328-1. Cylindrical Gears-ISO System of Flank Tolerance Classification-Part. 1: Definitions and Allowable Values of Deviations Relevant to Flanks of Gear Teeth. Available online: https://www.iso.org/obp/ ui/\#iso:std:iso:1328:-1:ed-2:v1:en (accessed on 6 September 2020).

Publisher's Note: MDPI stays neutral with regard to jurisdictional claims in published maps and institutional affiliations.

(C) 2020 by the authors. Licensee MDPI, Basel, Switzerland. This article is an open access article distributed under the terms and conditions of the Creative Commons Attribution (CC BY) license (http://creativecommons.org/licenses/by/4.0/). 